\title{
Trade Costs, Quality, and The Skill Premium
}

\author{
Eddy Bekkers* \\ University of Bern \\ Joseph Francois ${ }^{\ddagger}$ \\ University of Bern and CEPR (London) \\ Miriam Manchin ${ }^{\S}$ \\ University College London
}

\begin{abstract}
We develop a monopolistic competition model with nonhomothetic factor input bundles where increasing quality requires increasing use of skilled workers. As a result more skill abundant countries export higher quality, higher priced goods. Using a multicountry dataset we test and confirm the findings in Schott (2004) of a positive effect of skill abundance on unit values identified with US data. We extend the core model with per unit trade costs leading to the Washington-apples effect that goods shipped over larger distance are of higher quality. The combination of high-quality goods being relatively skill intensive with the Washington-apples effect implies that countries at a larger distance from their trading partners display a higher skill premium. Simulating our model we find that a doubling of distance of a country relative to all its trading partners raises the skill premium in a country by about 2.3 percent.
\end{abstract}

Keywords: Traded goods prices, exporter skill abundance, nonhomothetic factor inputs, per unit trade costs, skill premium

JEL codes: F12, F14

printdate: October 11, 2015

\footnotetext{
${ }^{*}$ We want to thank Jean Marie Viaene, Felix Lamp and Octavio Fernandez-Amador for useful comments and discussions. All possible errors are ours. Corresponding Address: University of Bern, World Trade Institute, Hallerstrasse 6. 3012 Bern, Switzerland. +41316313270.

†eddybekkers@gmail.com

†joseph.francois@wti.org

§m.manchin@ucl.ac.uk
} 


\section{Trade Costs, Quality, and The Skill Premium}

ABSTRACT: We develop a monopolistic competition model with nonhomothetic factor input bundles where increasing quality requires increasing use of skilled workers. As a result more skill abundant countries export higher quality, higher priced goods. Using a multicountry dataset we test and confirm the findings in Schott (2004) of a positive effect of skill abundance on unit values identified with US data. We extend the core model with per unit trade costs leading to the Washington-apples effect that goods shipped over larger distance are of higher quality. The combination of high-quality goods being relatively skill intensive with the Washington-apples effect implies that countries at a larger distance from their trading partners display a higher skill premium. Simulating our model we find that a doubling of distance of a country relative to all its trading partners raises the skill premium in a country by about 2.3 percent.

Keywords: Traded goods prices, exporter skill abundance, nonhomothetic factor inputs, per unit trade costs, skill premium

JEL codes: F12, F14

\section{Introduction}

In a seminal paper based on U.S. import data, Schott (2004) found that traded goods prices within detailed product categories rise in the skill and capital abundance of the exporting country. As such he provided evidence for within-sector specialization. Broadly speaking, goods prices vary systematically even for similar goods sharing the same detailed product classification. More skill-abundant and capital-abundant countries export goods with higher prices. Higher prices are taken as evidence of higher quality.

While Schott's (2004) findings highlight the importance of exporter characteristics, and especially skill abundance in exporting countries, the theoretical literature that followed has focused instead on explanations based on distance and importer characteristics in explaining international pricing patterns. ${ }^{1}$ The related empirical literature has also followed this route. As such, we are left with evidence based largely on one country, the U.S., with respect to exporter characteristics.

\footnotetext{
${ }^{1}$ Manova and Zhang (2012), Verhoogen (2008), Kugler and Verhoogen (2012), Crozet, et al. (2012), Martin (2012), Görg, et al. (2010), Bastos and Silva (2010), Hallak and Sivadasan (2010) are examples of studies with firm level prices. Hummels and Skiba (2004), Hummels and Lugovskyy (2009), Baldwin and Harrigan (2011), Harrigan, et al. (2011) and Bekkers, et al. (2012) use average prices at various HS levels.
} 
In this paper we return to Schott's original observations on exporters and test his findings on the effect of skill abundance on traded goods prices employing a multicountry dataset with multiple exporters and importers. Compared to Schott, our data allow for inclusion of various fixed effects to control for possible omitted variables and we also estimate non-linear specifications. After the empirical exercise we model the link between skill abundance and pricing in a monopolistic competition framework with homogeneous firms in the spirit of Krugman (1980), adding a role for quality. So, preferences are CES including a taste parameter as a measure for quality. We work with a variant of the Krugman model developed by Venables (1994) with fixed export costs besides regular fixed costs. ${ }^{2}$ This implies separate free entry conditions for each destination market and the possibility that only a subset of firms export. There are two factor inputs, high skilled and low skilled labor, and factor input bundles are non-homothetic. Goods with higher quality require relatively more skilled labor. Moreover, similar to Baldwin and Harrigan (2011) and Feenstra and Romalis (2014), the marginal cost parameter rises with quality. This setup gives a straightforward explanation for the relation between exporter skill abundance and traded goods prices in Schott (2004). In relatively skill abundant countries the relative wage of skilled workers is lower, implying a lower cost of producing high quality goods. This raises the incentive for firms to produce higher quality goods. And goods of higher quality display higher marginal costs raising the price.

We first define a basic model to analytically derive the impact of skill abundance on traded goods prices. Then we extend the basic framework with two additional elements from the literature on traded goods prices and solve the model with simulations. First, we add per unit trade costs to the model, besides the standard iceberg trade costs. This generates a Washington apples effect as in Hummels and Skiba (2004). Goods shipped at larger distance have a higher quality. Second, we include a taste for quality parameter on the demand side and following Hallak (2006) this parameter is a function of income per capita. This implies that richer consumers demand higher quality goods. With quality being relatively skill-intensive countries at a larger distance from their trading partners will produce higher quality goods raising the relative demand for skilled workers and thus the skill premium.

We solve the extended model numerically calibrating it to actual income, income per

\footnotetext{
${ }^{2}$ The model setup of Venables (1994) with destination specific fixed costs is chosen to keep the model tractable enough to derive analytical results. Generating an effect of skill abundance on quality requires a non-homothetic cost function. This reduces the tractability of the model implying that we need to keep other modelling features as basic as possible. As we are interested in explaining aggregate traded goods prices and not firm level prices, we can abstract from firm heterogeneity as used for example in Bernard, et al. (2007).
} 
capita and distance data for the largest countries in the empirics. Parameters appearing in Feenstra and Romalis (2014) are set as estimated by these scholars. The remaining parameters are taken from the literature and set such that the estimated elasticities of the fob-price with respect to skill abundance and distance employing data following from model simulations are close to the elasticities estimated with real-world data. Model simulations show that the combination of per unit trade costs and high-quality goods being skill intensive generates an intuitive relationship between trade costs and the skill premium. An increase in distance raising per unit trade costs relative to ad valorem trade costs generates a Washington apples effect, raises the quality of exporter's goods and therefore also the demand for skilled workers. Simulations show that a doubling of distance of a country from its trading partners raises the skill premium by 2.3 percent. Our simulations indicate that there is also a demand-side effect on the distribution of income. Richer consumers benefit more from quality increases as quality as they have a higher valuation for quality. This reinforces the effect on the nominal skill premium, although the effect in our simulations is an order smaller than the effect on the nominal skill premium.

Based on the above exposition our contribution to the literature is thus twofold. First, we introduce a mechanism through which distance affects the skill premium as a result of the combination of the Washington apples effect and the relative skill intensity of high quality goods. Second, we provide an evaluation of Schott's U.S. based results with respect to factor abundance using a wider dataset on traded goods prices with multiple importers and exporters.

For the empirics we employ a large, multi-country dataset with product level (HS6) unit values for the period 2000-2004. The empirics confirm the main prediction of our model and the findings in Schott (2004). A larger relative skill abundance of the exporting country leads to higher traded goods prices. Based upon our model we also examine the effect of distance and exporter gdp per capita on unit values. We include an importerproduct-time fixed effect to capture the role of importer gdp per capita and variation in the definition of unit values across products. With this fixed effect we can also account for other relevant demand side variables not present in our theoretical model like market size and income inequality. The coefficients on distance and exporter gdp per capita have the expected positive signs. We estimate the same model including nonlinear terms. The results confirm the findings of the (log) linear model with marginal effects close to the linear specification.

The related literature can be split up into three parts, first work on explaining traded 
goods prices, second work on between country differences in the incentive to produce quality and third work on trade and inequality. Most theoretical work explaining traded goods prices focuses on demand side characteristics ${ }^{3}$, on distance ${ }^{4}$ or on firm characteristics. ${ }^{5}$ The work by Feenstra and Romalis (2014) includes many elements of this literature. Feenstra and Romalis (2014) set up a firm heterogeneity model of quality differentiation with per unit trade costs and demand for quality varying with importer income per capita. They estimate model parameters structurally, using trade and price data. In our model simulations we build on Feenstra and Romalis (2014), by using their estimated elasticities and extending their framework with a role for factor abundance on the supply side.

Flam and Helpman (1987), Hummels and Klenow (2005) and Fieler (2012) also model between country differences in the incentive to produce and export goods of different quality. In these papers differences in the ability to produce quality stem from absolute productivity differences between countries, but are not related to factor abundance. 6 Early work related to our paper is Falvey (1981), who develops a specific factors model to explain intra-industry trade as a result of factor differences between countries. Although his model also features quality differentiation endogenous to factor differences, he does not purport to relate prices to country characteristics and instead focuses on explaining intra-industry trade with factor differences. ${ }^{7}$

Fajgelbaum, et al. (2011) combine non-homothetic preferences with increasing returns in production, showing that richer countries specialize in the production of high-quality goods. Although our extended model also contains non-homothetic preferences, there is no home-market effect of quality specialization in our model. The reason is that quality and fixed costs are destination-specific: firms have to pay fixed costs to enter each market and sell a different quality level to each country. So, having a large home market for high-quality goods does not imply that high-quality goods are also exported by more firms. Dingel (2014) models the two mechanisms in Schott (2004) and Fajgelbaum, et al. (2011) leading to a positive effect of exporter income per capita on the quality of exports

\footnotetext{
${ }^{3}$ See for example Flam and Helpman (1987), Hallak (2006), Hsieh and Klenow (2007), Hummels and Lugovskyy (2009), Simonovska (2010), Alessandria and Kaboski (2011) and Bekkers, et al. (2012)

${ }^{4}$ See among others Hummels and Skiba (2004), Baldwin and Harrigan (2011).

${ }^{5}$ See among others Verhoogen (2008), Kugler and Verhoogen (2012), Hallak and Sivadasan (2010)

${ }^{6}$ Kugler and Verhoogen (2012) relate the quality of output to quality of inputs in a model where more productive firms use higher quality inputs, because of complementarity between productivity and input quality.

${ }^{7}$ Bekkers (2013) proposes a different mechanism to explain the effect of skill abundance on quality and traded goods prices. In a firm heterogeneity model, firms can raise the quality of their goods by investing more in innovation. With factor input bundles in innovation being relatively skill intensive, more skill abundant countries produce higher quality, higher priced goods.
} 
and determines the relative importance of the two mechanisms with data on intra-US trade. Our model does not feature the home-market effect. Instead we include per unit trade costs generating an effect of distance on the skill premium, also solving our model numerically to quantify the effect.

The recent literature on trade and inequality has proposed various mechanisms to explain rising inequality in all countries as a result of trade liberalization, moving away from the traditional Heckscher-Ohlin framework where inequality effects differ according to relative factor abundance of the country. Four sets of studies are related to our work. First, Verhoogen (2008) shows how trade liberalization can raise wage inequality in a firm heterogeneity model where more productive firms produce higher quality goods and pay higher wages. Trade liberalization will reallocate market shares towards more productive exporting firms paying higher wages and thus raising wage inequality. Burstein and Vogel (2012) and Harrigan and Reshef (2011) model a similar mechanism in a firm heterogeneity model with more productive firms being more skill intensive. Trade liberalization reallocates market shares towards more productive and more skill intensive firms, raising the demand for skills and thus the skill premium. Similar to these models, in our model higher quality goods (or more productive firms) are also more skill intensive. The way in which changes in trade costs generate more demand for quality instead is different. In the mentioned studies this occurs through a reallocation effect towards more productive firms and in our paper this occurs through a change in the strength of the Washington-apples effect: when per unit trade costs become more important relative to ad valorem trade costs, the demand for quality rises. Second, Caron, et al. (2011) show that there is a positive relation between the sectoral income elasticity of demand and the skill intensity, implying that rising income will lead to increased demand for skills thus raising the skill premium. ${ }^{8}$ Our model features a similar mechanism, as rising income (possibly as a result of trade liberalization) raises the demand for high-quality and thus more skill-intensive goods. Third, Matsuyama (2007) shows that trade can drive up inequality if activities related to international business are relatively skill intensive. Fourth, Fajgelbaum and Khandelwal (2014) show that trade affects the income distribution through the demand side under non-homothetic preferences, a mechanism also present in our model. Fajgelbaum and Khandelwal (2014) find that trade in general is good for poor consumers.

The next section starts with an analysis of the multi-country price data providing motivating evidence for the theoretical model. Section 3 outlines both the baseline theoretical model on the role of factor abundance and the model with extensions. In section 4

\footnotetext{
${ }^{8}$ The published version, Caron, et al. (2014), does not discuss the skill premium implications.
} 
we present a numerical analysis of the extended theoretical model and section 5 concludes.

\section{Motivating Evidence}

Before developing a theoretical model we first explore the link between traded goods prices and skill abundance with a multicountry dataset, extending the work by Schott (2004) who employed only data on exports to the US. We proxy traded goods prices with unit values. The data used for unit values come from the BACI database ${ }^{9}$ which contains quantity and the value of bilateral imports in 6-digit Harmonized System (HS) classification. The database is constructed from COMTRADE (Commodities Trade Statistics database). We use data for the period between 2000-2004. BACI takes advantage of the double information on each trade flow to fill out the matrix of bilateral world trade providing a "reconciled' value for each flow reported at least by one of the partners. Therefore the missing values in BACI are those concerning trade between non reporting countries.

Skill abundance and income per capita data originate from the World Bank's World Development Indicator database. We use GDP per capita as a measure of income per capita. Similarly to Schott (2004) we define skilled labor as workers with tertiary or secondary education, while unskilled labor as having only primary education. Data on distance are taken from Clair et al (2004). ${ }^{10}$ Some descriptive statistics on our sample and the list of countries used in the regressions based upon data availability can be found in Appendix C

We include distance in all regressions to account for the Washington apples effect meaning that quality rises with distance, an empirical finding first discovered by Alchian and Allen (1964) and explored in a trade setting by Hummels and Skiba (2004). We control for the role of demand side variables like importer market size and importer income inequality by including importer-time-product fixed effects. The product specific fixed effects serve to account for differences in measurement of unit values across products.

Table 1 presents the estimation results. In column 1 we start with a linear specification with distance and skill abundance as explanatory variables and in column 2 we add GDP per capita as a control variable. Our results are in line with the empirical results of Schott (2004) who found a positive effect of exporter skill abundance on unit values with US importer data. We further explore similarities and differences between our results and Schott (2004) in Appendix B. Controlling for GDP per capita the coefficient on skill

\footnotetext{
${ }^{9}$ http://www.cepii.fr/anglaisgraph/bdd/baci/baciwp.pdf

${ }^{10} \mathrm{http}: / /$ www.cepii.fr/anglaisgraph/bdd/distances.htm. The distance data are calculated following the great circle formula, which uses latitudes and longitudes of the relevant capital cities.
} 
abundance drops from 0.095 and 0.057. Due to the correlation with GDP per capita, the coefficient becomes lower once GDP per capita is also included. Our estimation results imply that a $10 \%$ increase in relative skill abundance is associated with an increase in traded goods prices of between $0.9 \%$ and $0.6 \%$. We find that prices increase with distance supporting the Washington-apples effect. Furthermore, GDP per capita of the exporter country has a positive effect on export unit values throughout all specifications with a coefficient between 0.19 and 0.15 .

To check for nonlinearities we add nonlinear terms (squares and interaction terms) in column 3 with the marginal effects displayed in column 4 . The interaction term between skill abundance $\ln \frac{S}{U}$ and GDP per capita is significant, implying that some of the effects are nonlinear. The marginal effects are very close to the coefficients of the linear specification.

In column 5 we use sector and importer-country specific estimates of the product substitution elasticity estimated by Broda, et al. (2006) to examine the interaction effect of skill abundance in exporter countries with the product substitution elasticity in importer countries. ${ }^{11}$ Broda, et al. (2006) estimate the substitution elasticities for 73 countries at the HS6 level. ${ }^{12}$ The coefficient of the interaction term is negative and non-significant. ${ }^{13}$ Below we will show that effects are similar in the simulations with our theoretical model displaying a very small effect of the substitution elasticity on the impact of skill abundance on traded goods prices.

Finally we evaluate the importance of exporting fixed costs and the extensive margin for traded goods prices. Columns six and seven show that measures of both variables are insignificant. As will be discussed below this is in line with simulations with the theoretical model, where these variables are also insignificant. ${ }^{14}$

To summarize, our estimation results indicate that countries export higher priced, higher quality products when they are more skill abundant. They thus show that the results of Schott (2004) also hold when we take a wider sample of importing countries beyond the US, although the impact of relative skill abundance is a bit lower for the larger sample of importing countries (see for further discussion on the comparison between Schott (2004) and our results Appendix B).

\footnotetext{
${ }^{11}$ We cannot include the measure itself as we have sectoral fixed effects

${ }^{12}$ The data can be downloaded from http://www.columbia.edu/ dew35/TradeElasticities/TradeElasticities.html

${ }^{13}$ We also explored the interaction effect with $\sigma$ in the nonlinear model and effects are very similar. Results are available upon request.

${ }^{14}$ Controlling also for GDP per capita, the extensive margin measure becomes significant with a positive sign. This result is hard to interpret and so we conclude that the effect of the extensive margin is not robust to variation in control variables.
} 
Table 1: Effect of relative skill abundance, control variables and interactions with substitution elasticities on unit values

\begin{tabular}{|c|c|c|c|c|c|c|c|}
\hline $\begin{array}{l}\text { Dependent variable: } \\
\ln U V_{k l m t}\end{array}$ & (1) & $(2)$ & (3) & $\begin{array}{c}(4) \\
\text { marg effects }\end{array}$ & (5) & (6) & (7) \\
\hline $\ln (S / U)$ & $\begin{array}{c}0.095^{* * *} \\
(0.025)\end{array}$ & $\begin{array}{c}0.057^{* * *} \\
(0.017)\end{array}$ & $\begin{array}{l}-0.009 \\
(0.131)\end{array}$ & $\begin{array}{c}0.094^{* * *} \\
(0.023)\end{array}$ & $\begin{array}{l}0.57^{* * *} \\
(0.017)\end{array}$ & $\begin{array}{c}0.095^{* * *} \\
(0.025)\end{array}$ & $\begin{array}{c}0.094^{* * *} \\
(0.025)\end{array}$ \\
\hline ln distance & $\begin{array}{c}0.116^{* * *} \\
(0.016)\end{array}$ & $\begin{array}{c}0.129^{* * *} \\
(0.017)\end{array}$ & $\begin{array}{l}0.257^{*} \\
(0.144)\end{array}$ & $\begin{array}{c}0.127^{* * *} \\
(0.018)\end{array}$ & $\begin{array}{c}0.129^{* * *} \\
(0.017)\end{array}$ & $\begin{array}{c}0.112^{* * *} \\
(0.016)\end{array}$ & $\begin{array}{c}0.116^{* * *} \\
(0.016)\end{array}$ \\
\hline $\ln G D P p c$ & & $\begin{array}{c}0.150^{* * *} \\
(0.022)\end{array}$ & $\begin{array}{l}-0.045 \\
(0.129)\end{array}$ & $\begin{array}{c}0.191^{* * *} \\
(0.035)\end{array}$ & $\begin{array}{c}0.150^{* * *} \\
(0.022)\end{array}$ & & \\
\hline exportfc & & & & & & $\begin{array}{c}0.007 \\
(0.006)\end{array}$ & \\
\hline extmarg & & & & & & & $\begin{array}{l}-3.406 \\
(2.667)\end{array}$ \\
\hline$(\ln (S / U))^{2}$ & & & $\begin{array}{c}0.13 \\
(0.011)\end{array}$ & & & & \\
\hline $\ln (S / U) \ln$ distance & & & $\begin{array}{l}-0.008 \\
(0.013)\end{array}$ & & & & \\
\hline $\ln (S / U) \ln G D P p c$ & & & $\begin{array}{l}0.048^{* *} \\
(0.022)\end{array}$ & & & & \\
\hline $\ln G D P p c \ln$ distance & & & $\begin{array}{c}0.005 \\
(0.012)\end{array}$ & & & & \\
\hline$(\ln G D P p c)^{2}$ & & & $\begin{array}{c}0.026 \\
(0.016)\end{array}$ & & & & \\
\hline$(\ln \text { distance })^{2}$ & & & $\begin{array}{l}-0.008 \\
(0.009)\end{array}$ & & & & \\
\hline $\ln (S / U) * \ln \sigma$ & & & & & $\begin{array}{l}-2.28 \mathrm{e}-0.6 \\
(5.38 \mathrm{e}-06)\end{array}$ & & \\
\hline Constant & $\begin{array}{c}1.536 \\
(0.132)\end{array}$ & $\begin{array}{c}1.035^{* * *} \\
(0.152)\end{array}$ & $\begin{array}{c}0.739 \\
(0.577)\end{array}$ & & $\begin{array}{c}1.541^{* * *} \\
(0.152)\end{array}$ & $\begin{array}{c}1.541^{* * *} \\
(0.139)\end{array}$ & $\begin{array}{c}1.543^{* * *} \\
(0.134)\end{array}$ \\
\hline Observations & $23,632,862$ & $23,632,862$ & $23,632,862$ & & $23,632,862$ & $23,174,457$ & $23,632,862$ \\
\hline Adjusted $R^{2}$ & 0.62 & 0.63 & 0.63 & & 0.63 & 0.62 & 0.62 \\
\hline
\end{tabular}

Standard errors (in parentheses) are clustered by exporters. Importer-product-time fixed effects are included in all specifications. $\ln (S / U)$ is the exporter's skill abundance defined as the log of the ratio of skilled to unskilled workers. In distance is the log of distance between the exporter and importer country capitals. $\ln G D P p c$ is the log of GDP per capita of the exporter country in 1000 dollars. $\ln \sigma$ is the product substitution elasticity

${ }^{*} p<0.10,{ }^{* *} p<0.05,{ }^{* * *} p<0.01$ 


\section{Theoretical Model}

The modelling setup follows Venables (1994), adding endogenous quality and nonhomothetic factor cost bundles. We model an economy with two countries indexed by $k, l=H, F$, two factors of production, skilled workers $S$ and unskilled workers $U$. All workers in the two countries have identical preferences.

\subsection{Demand}

Utility in country $k, Q_{k}$, consists of a CES composite of domestic varieties $Q_{k k}$ and foreign varieties $Q_{l k}$ with substitution elasticity $\varepsilon$. Preferences for both domestic and foreign varieties are a CES function over a continuum of varieties $\omega \in \Omega_{k k}$ and $\omega \in \Omega_{l k}$ with substitution elasticity $\sigma$ :

$$
\begin{aligned}
Q_{k} & =\left(Q_{k k}^{\frac{\varepsilon-1}{\varepsilon}}+Q_{l k}^{\frac{\varepsilon-1}{\varepsilon}}\right)^{\frac{\varepsilon}{\varepsilon-1}} \\
Q_{l k} & =\left[\int_{\omega \in \Omega_{l k}}(z(\omega) q(\omega))^{\frac{\sigma-1}{\sigma}} d \omega\right]^{\frac{\sigma}{\sigma-1}}
\end{aligned}
$$

$q_{\omega}$ and $z_{\omega}$ are respectively the quantity and quality of variety $\omega$. Variables with a subscript $l k$ represent flows from country $l$ to country $k$. Demand for variety $\omega$ by all consumers in country $k$ imported from country $l$ is given by:

$$
q_{l k}(\omega)=z_{l k}(\omega)^{\sigma-1} p_{l k}(\omega)^{-\sigma} P_{l k}^{\sigma-\varepsilon} P_{k}^{\varepsilon-1} I_{k}
$$

The price index $P_{k}$ and $P_{l k}$ are defined as:

$$
\begin{aligned}
P_{k} & =\left(P_{k k}^{1-\varepsilon}+P_{l k}^{1-\varepsilon}\right)^{\frac{1}{1-\varepsilon}} \\
P_{l k} & =\left[\int_{\omega \in \Omega_{l k}}\left(\frac{p(\omega)}{z(\omega)}\right)^{1-\sigma} d \omega\right]^{\frac{1}{1-\sigma}}
\end{aligned}
$$

$I_{k}$ is total income in country $k$ and the sum of skilled and unskilled labor's income:

$$
I_{k}=w_{k}^{s} S_{k}+w_{k}^{u} U_{k}
$$

$w_{k}^{s}$ and $w_{k}^{u}$ are respectively the wages of skilled and unskilled workers and $S_{k}$ and $U_{k}$ the number of skilled and unskilled workers. 


\subsection{Supply}

We now turn to the supply side. Like in Krugman (1980) firms are identical and can produce with an identical increasing returns technology with a fixed cost $f$. Following Venables (1994) firms have to pay market specific fixed costs. ${ }^{15}$ So a firm from country $k$ pays domestic fixed costs to sell in its home market, $f_{k k}$ and additional exporting fixed costs $f_{k l}$ to sell abroad. We can interpret the fixed costs as beachhead costs to enter a market. Beachhead costs for each market are intuitive in a setting where firms produce different quality levels for different destination markets depending on market conditions in the destination. Destination specific fixed costs also enable us to derive analytical results in the basic model. As explained by Venables (1994) a setup with an upper Armington nest together with destination specific fixed costs implies selection into exporting with only a subset of firms exporting. Without the Armington nest, the four free entry conditions (two for each country) following from destination specific fixed costs would not be independent and thus not allow for both trading and non-trading firms. Selection is a property of our model setup, but is not important for the results on traded goods prices in the basic model as firms are homogeneous and per unit trade costs are absent. In the extended model with per unit trade costs changes in the number of exporting firms (the extensive margin) might affect traded goods prices, since per unit trade costs imply that exported goods are of higher quality.

Marginal costs for sales to a specific destination (domestic and exporting) are a function of the quality of the good sold in the destination with an elasticity $1 / \theta$. $\theta$ is called the quality elasticity in Baldwin and Harrigan (2011) and it is a measure for the ability to produce high quality goods. ${ }^{16}$ Also Feenstra and Romalis (2014) work with this relation between quality and marginal costs. The total cost function $C_{k}$ of a firm from country $k$ is given by:

$$
C_{k}\left(z_{k k}, z_{k l}, w_{k s}, w_{k u}\right)=\sum_{l=H, F}\left(z_{k l}^{\frac{1}{\theta}} \tau_{k l} q_{k l}+f_{k l}\right) C B_{k l}
$$

$\tau_{k l}$ are iceberg trade costs. $C B_{k l}$ is the cost of input bundles used in production and fixed costs and defined as follows:

$$
C B_{k l}=C B\left(z_{k l}, w_{k s}, w_{k u}\right)=\left(\left(z_{k l}^{\eta} w_{k}^{s}\right)^{1-\rho}+\vartheta\left(w_{k}^{u}\right)^{1-\rho}\right)^{\frac{1}{1-\rho}}
$$

We assume $\eta>0$. The expression for the cost of input bundles in (8) implies that an

\footnotetext{
${ }^{15}$ Also Jean (2002) and Melitz (2003) work with fixed export costs.

${ }^{16}$ To be precise, the quality elasticity as defined in Baldwin and Harrigan (2011) is equal to $\theta-1$ in our model.
} 
increase in quality raises the weight of skilled workers in the input bundle. Therefore, relatively more high skilled workers are required for higher quality goods. So, the cost function is non-homothetic and to allow for variation in the substitution elasticity between high skilled and low skilled workers, we work with a nonhomothetic CES cost function as in Shimomura (1999) with $\rho$ the substitution elasticity between skilled and unskilled labor in the cost of input bundles in (8). ${ }^{17} \vartheta$ is a CES-shifter used in the calibration to generate a positive skill-premium, i.e. $w_{k}^{s}>w_{k}^{u}$.

We choose the functional form $z_{k l}^{\eta}$ for the CES-weight to be able to derive analytical results on the effects of skill abundance on quality and traded goods prices in the baseline model. With our specification costs depend on quality through marginal costs and through the non-homotheticity of the input bundles.

Using the expression for demand in equation (3) and the cost function as specified in equation (7), each firm maximizes profits $\pi_{k}$ choosing the price $p_{k l}$ and quality $z_{k l}$ :

$$
\pi_{k}=\sum_{l=H, F}\left(\left(\frac{p_{k l}}{z_{k l}}\right)^{1-\sigma} P_{k l}^{\sigma-\varepsilon} P_{l}^{\varepsilon} I_{l}-\left(z_{k l}^{\frac{1}{\theta}+\sigma-1} \tau_{k l} p_{k l}^{-\sigma} P_{k l}^{\sigma-\varepsilon} P_{l}^{\varepsilon} I_{l}+f_{k l}\right) C B_{k l}\right)
$$

Each firm produces a unique variety. Maximizing profits with respect to the price $p_{k l}$ generates the following markup equation for the cif price:

$$
p_{k l}=\frac{\sigma}{\sigma-1} z_{k l}^{\frac{1}{\theta}} \tau_{k l} C B_{k l}
$$

Taking the first order condition of profit in equation (9) with respect to quality and substituting the markup pricing equation in (10) leads to:

$$
\frac{p_{k l} q_{k l}}{\sigma}\left(\frac{(\sigma-1) \frac{\theta-1}{\theta}}{z_{k l}}+\frac{\sigma-1}{C B} \frac{\partial C B}{\partial z_{k l}}\right)+f_{k l} \frac{\partial C B}{\partial z_{k l}}=0
$$

The domestic and exporting market can be seen as separate markets, because there are fixed exporting costs besides regular fixed costs. Entering the domestic market and paying the domestic beachhead cost does not imply that a firm can also export as in Krugman (1980). This implies that there are two separate zero profit conditions, one for

\footnotetext{
${ }^{17}$ The production function corresponding to the cost function $C B$ in equation (8) is given by $Y\left(z_{k m}, U_{k}, S_{k}\right)=\left(\left(\frac{S_{k}}{z_{k m}^{\eta}}\right)^{\frac{\rho-1}{\rho}}+\vartheta^{\frac{1}{\rho}} U_{k}^{\frac{\rho-1}{\rho}}\right)^{\frac{\rho}{\rho-1}}$.
} 
the domestic market and one for the exporting market: ${ }^{18}$

$$
\frac{p_{k l} q_{k l}}{\sigma}=f_{k l} C B_{k l}
$$

The derivative of $C B_{k l}$ in equation (8) with respect to $z_{k l}$ is equal to:

$$
\frac{\partial C B_{k l}}{\partial z_{k l}}=\frac{\eta C B_{k l}^{\rho}\left(z_{k l}^{\eta} w_{k}^{s}\right)^{1-\rho}}{z_{k l}}
$$

Substituting the zero profit conditions in equations (12) and the expression for $\frac{\partial C B}{\partial z_{k l}}$ into equation (11) leads to:

$$
\frac{(\sigma-1) \frac{\theta-1}{\theta}}{z_{k l}}-\frac{\sigma \eta\left(z_{k l}^{\eta} w_{k}^{s}\right)^{1-\rho}}{z_{k l} C B_{k l}^{1-\rho}}=0
$$

The first term in equation (14) represents the balance of the marginal benefit of higher quality as a result of larger sales and the increase in marginal cost of higher quality. The second term represents the marginal cost of higher quality due to a larger required use of the more expensive skilled labor. The balance of the two determines the optimal level of quality.

Using the expression for $C B_{k l}$ in equation (8), equation (14) can be rewritten to express the relative wage $\frac{w_{k}^{s}}{w_{k}^{u}}$ as a function of quality $z_{k l}$ with $\zeta$ defined as $\zeta=\frac{\sigma-1}{\sigma} \frac{\theta-1}{\theta} \frac{1}{\eta}$ :

$$
\frac{w_{k}^{u}}{w_{k}^{s}}=z_{k l}^{\eta}\left(\frac{1-\zeta}{\zeta}\right)^{\frac{1}{1-\rho}}
$$

\subsection{Effect of Skill Abundance}

To derive the effect of skill abundance on quality, we add the labor market equilibrium conditions for skilled and unskilled workers. Applying Shephard's lemma to the cost function in equation (7) and using the rewritten free entry conditions, $z_{k l}^{\frac{1}{\theta}} q_{k l}+f_{k l}=\sigma f_{k l}$, gives:

$$
\begin{gathered}
S_{k}=\sum_{l=H, F} N_{k l} \sigma f_{k l} C B_{k l}^{\rho}\left(z_{k l}^{\eta}\right)^{1-\rho}\left(w_{k}^{s}\right)^{-\rho} \\
U_{k}=\sum_{l=H, F} N_{k l} \sigma f_{k l} C B_{k l}^{\rho} \vartheta\left(w_{k}^{u}\right)^{-\rho}
\end{gathered}
$$

We can divide the labor market conditions in equations (16)-(17), using the fact that

\footnotetext{
${ }^{18}$ Venables (1994) works with one free entry condition for firms selling only in the domestic market and one free entry condition for firms selling in both markets. This is equivalent to our approach with a free entry condition for each market.
} 
quality $z_{k l}$ does not vary with the destination market without per unit trade costs and a role for importer gdp per capita. This leads to the following expression:

$$
\frac{S_{k}}{U_{k}}=\frac{\left(z_{k l}^{\eta}\right)^{1-\rho}}{\vartheta}\left(\frac{w_{k}^{u}}{w_{k}^{s}}\right)^{\rho}
$$

Substituting equation (15) into (18), we can solve for quality $z_{k l}$ as a function of relative skill abundance $S_{k} / U_{k}$ :

$$
z_{k l}=\left(\frac{1}{\vartheta} \frac{S_{k}}{U_{k}}\right)^{\frac{1}{\eta}}\left(\frac{\zeta}{1-\zeta}\right)^{\frac{1}{\eta} \frac{\rho}{1-\rho}}
$$

So, quality $z_{k l}$ rises in relative skill abundance $\frac{S_{k}}{U_{k}}$.

We can easily determine the effect of relative skill abundance on the export price. From equation (10) the export price $p_{k l}$ is determined by the level of quality $z_{k l}$ and the cost of input bundles $C B_{k l}$ :

$$
p_{k l}=\frac{\sigma}{\sigma-1}\left(\frac{S_{k}}{U_{k}}\right)^{\frac{1}{\eta \theta}}\left(\frac{\zeta}{1-\zeta}\right)^{\frac{\rho}{\eta(1-\rho) \theta}} \tau_{k l} C B_{k l}
$$

In Appendix A we show that the relative change of unit wage costs as a result of a change in the relative wage $\frac{w_{k}^{s}}{w_{k}^{u}}$ is zero when taking into account the endogenous reaction in quality. The direct effect of a larger relative skilled wage $\frac{w_{k}^{s}}{w_{k}^{u}}$ exactly cancels out against the effect of the reduction in quality induced by a larger relative skilled wage. So the costs of input bundles do not vary with relative wages. Hence, the effect of relative skill abundance is determined by the direct effect in equation (20) displaying an elasticity of the price $p_{k l}$ with respect to skill abundance of $\frac{1}{\eta \theta}$. So we have the following result:

Result 1 In the baseline model export goods from relatively more skill abundant countries have a larger quality and a higher price.

The model presented in this section contains a link between skill abundance, quality and market price. In a more skill abundant country, the relative wage of skilled workers is lower. Therefore, the marginal cost of producing higher quality goods falls. As a result firms will offer higher quality goods. ${ }^{19}$ The relations are consistent with the empirical findings by Schott (2004). A larger relative skill abundance in an exporting country leads to a higher export quality and a higher export price.

\footnotetext{
${ }^{19}$ Scope for quality differentiation implies that in our model larger relative skill abundance and thus relatively lower skilled wages lead to higher prices. This in contrast to the standard Heckscher-Ohlin factor abundance model where larger skill abundance and thus lower skilled wages lead to lower prices.
} 


\subsection{Model with Extensions}

In this section we add two additional features to the baseline skill abundance model, a taste for quality that is varying with income as in Hallak (2006) and per unit trade costs as in Hummels and Skiba (2004). With these extensions our model becomes close to the model in Feenstra and Romalis (2014) with two main differences. First, we extend the model with a role for skill abundance and second we limit the model by abstracting from firm heterogeneity and instead working with destination-specific fixed costs as in Venables (1994). Firm heterogeneity is not important for our paper since we focus on aggregate traded goods prices and not on firm-level prices. Moreover, since we cannot solve for quality explicitly with our extensions, firm heterogeneity would make simulations intractable.

The first additional feature is introduced as in Feenstra and Romalis (2014) using the dual approach starting from the expenditure function. The expenditure function $E_{k}^{v}$ of a worker of type $v, v=s, u$, is defined as

$$
\begin{aligned}
& E_{k}^{v}=Q_{k}^{v} P_{k}^{v}=Q_{k}^{v}\left(\sum_{l=1}^{K}\left(P_{l k}^{v}\right)^{1-\varepsilon}\right)^{\frac{1}{1-\varepsilon}} \\
& P_{l k}^{v}=\left[\int_{\omega \in \Omega_{l k}}\left(\frac{p(\omega)}{z(\omega)^{\alpha_{k}^{v}}}\right)^{1-\sigma} d \omega\right]^{\frac{1}{1-\sigma}}
\end{aligned}
$$

$K$ is the number of countries, not necessarily limited to $2 . \alpha_{k}^{v}$ measures the importance of quality for consumers in country $k$ and $\alpha_{k}^{v}$ is a function of utility of a worker of type $v$ in country $k, Q_{k}^{v}$ :

$$
\alpha_{k}^{v}=1+\lambda \ln Q_{k}^{v}
$$

The expenditure function differs across the two types of workers, since the importance of quality for consumers is a function of utility. Demand $q_{l k}(\omega)$ is the sum of demands of the two types of workers and follows from the expenditure function in (21)-(22):

$$
q_{l k}(\omega)=\sum_{v=s, u} q_{l k}^{v}(\omega)=p_{l k}(\omega)^{-\sigma} \sum_{v=s, u} z_{l k}(\omega)^{\alpha_{k}^{v}(\sigma-1)}\left(P_{l k}^{v}\right)^{\sigma-\varepsilon}\left(P_{k}^{v}\right)^{\varepsilon} Q_{k}^{v}
$$

Price $p_{l k}$ and quality $z_{l k}$ are the same for the two types of workers, since we assume that the fixed costs involved in developing a new variety are sufficiently large to make it unprofitable to sell the different types of workers goods with different quality levels.

The second extension to the baseline model consists of the inclusion of both iceberg 
trade $\operatorname{costs} \tau_{k l}$ and per unit trade costs $T_{k l}$. Per unit trade costs will generate a Washington apples effect that exported goods are of higher quality. The expression for total costs of a firm from country $k$ becomes:

$$
C_{k}\left(z_{k k}, z_{k l}, w_{k}^{s}, w_{k}^{u}\right)=\sum_{l=1}^{K}\left(\tau_{k l}\left(z_{k l}^{\frac{1}{\theta}} \frac{C B_{k l}}{\varphi_{k}}+T_{k l}\right) q_{k l}+\frac{C B_{k l}}{\varphi_{k}} f_{k l}\right)
$$

Following Feenstra and Romalis (2014), iceberg trade costs are paid over costs inclusive of per unit trade costs. $\varphi_{k}$ is a country-level productivity measure, transforming the number of skilled $S_{k}$ and unskilled workers $U_{k}$ into the effective number of skilled and unskilled workers, respectively $\widetilde{S}_{k}$ and $\widetilde{U}_{k}$ :

$$
\widetilde{S}_{k}=\varphi_{k} S_{k} ; \widetilde{U}_{k}=\varphi_{k} U_{k}
$$

The productivity term $\varphi_{k}$ is introduced to be able to calibrate income per capita to a desired level.

Employing the expression for $C B_{k l}$ in equation (8) and the free entry condition, $p_{k l} q_{k l}=\frac{\sigma f_{k l} C B_{k l}}{\varphi_{k}}$, profit maximization generates the following markup pricing equation and first order condition for quality: ${ }^{20}$

$$
\begin{gathered}
p_{k l}=\frac{\sigma}{\sigma-1} \tau_{k l}\left(z_{k l}^{\frac{1}{\theta}} \frac{C B_{k l}}{\varphi_{k}}+T_{k l}\right) \\
\sum_{v=s, u} \chi_{k l}^{v} \alpha_{l}^{v}\left(z_{k l}^{\frac{1}{\theta}} \frac{C B_{k l}}{\varphi_{k}}+T_{k l}\right)-\frac{1}{\theta} z_{k l}^{\frac{1}{\theta}} \frac{C B_{k l}}{\varphi_{k}}+\left(\frac{\sigma \frac{C B_{k l}}{\varphi_{k}} z_{k l}^{\frac{1}{\theta}}+T_{k l}}{\sigma-1}\right) \frac{\eta\left(z_{k l}^{\eta} w_{k}^{s}\right)^{1-\rho}}{C B_{k l}^{1-\rho}}=0
\end{gathered}
$$

With the share of spending by workers of type $v=s, u$ in country $l$ on goods from country $k, \chi_{k l}^{v}$, given by:

$$
\chi_{k l}^{v}=\frac{p_{k l} q_{k l}^{v}}{p_{k l} q_{k l}}=\frac{z_{k l}^{\alpha_{l}^{v}(\sigma-1)}\left(P_{k l}^{v}\right)^{\sigma-\varepsilon}\left(P_{l}^{v}\right)^{\varepsilon} Q_{l}^{v}}{\sum_{w=s, u} z_{k l}^{\alpha_{l}^{w}(\sigma-1)}\left(P_{k l}^{w}\right)^{\sigma-\varepsilon}\left(P_{l}^{w}\right)^{\varepsilon} Q_{l}^{v}}
$$

The first term in equation (28) is the marginal benefit of higher quality as a result of larger sales. The second term represents the direct marginal cost of higher quality and the third term represents the marginal cost of higher quality due to a larger required use of the more expensive skilled labor both in variable costs and fixed costs. The balance of the three terms determines the optimal level of quality.

\footnotetext{
${ }^{20}$ Derivation in Appendix A. Because of the two income groups we cannot work with quality-adjusted price and quantity as in Feenstra and Romalis (2014) to derive the first order condition.
} 
The FOC for quality $z_{k l}$ nests both our baseline model and the model in Feenstra and Romalis (2014). Setting $\alpha_{l}^{v}$ at 1 and $T_{k l}$ at 0 , the FOC in equation (28) will be identical to the FOC in the baseline model. Setting $\eta$ at zero and thus eliminating the third term in equation (28) and equating $\alpha_{l}^{v}$ across the two income groups, $\alpha_{l}^{v}=\alpha_{l}$, leads to the same (explicit) solution for quality $z_{k l}$ as in Feenstra and Romalis (2014), $z_{k l}^{\frac{1}{\theta}}=\frac{\theta \alpha_{l} T_{k l}}{1-\theta \alpha_{k}} \frac{\varphi_{k}}{C B_{k l}} \cdot{ }^{21}$

The inclusion of the productivity shifter $\varphi_{k}$ and per unit trade costs $T_{k l}$ implies that the expressions for labor market equilibrium become:

$$
\begin{gathered}
S_{k}=\sum_{l=1}^{K} N_{k l}\left(\frac{\sigma \frac{C B_{k l}}{\varphi_{k}} z_{k l}^{\frac{1}{\theta}}+T_{k l}}{\frac{C B_{k l}}{\varphi_{k}} z_{k l}^{\frac{1}{\theta}}+T_{k l}}\right) \frac{f_{k l}}{\varphi_{k}} C B_{k l}^{\rho}\left(z_{k l}^{\eta}\right)^{1-\rho}\left(w_{k}^{s}\right)^{-\rho} \\
U_{k}=\sum_{l=1}^{K} N_{k l}\left(\frac{\sigma \frac{C B_{k l}}{\varphi_{k}} z_{k l}^{\frac{1}{\theta}}+T_{k l}}{\frac{C B_{k l}}{\varphi_{k}} z_{k l}^{\frac{1}{\theta}}+T_{k l}}\right) \frac{f_{k l}}{\varphi_{k}} C B_{k l}^{\rho} \vartheta\left(w_{k}^{u}\right)^{-\rho}
\end{gathered}
$$

To complete the characterization of equilibrium, we need to determine the number of domestic and exporting firms in each country, respectively $N_{k k}$ and $N_{k l}$, for which we use two equations. First, the expenditures to factor payments can be expressed as follows:

$$
\sum_{l=1}^{K} N_{k l}\left(\frac{\sigma z_{k l}^{\frac{1}{\theta}} \frac{C B_{k l}}{\varphi_{k}}+T_{k l}}{z_{k l}^{\frac{1}{\theta}} \frac{C B_{k l}}{\varphi_{k}}+T_{k l}}\right) f_{k l} \frac{C B_{k l}}{\varphi_{k}}=w_{k}^{u} U_{k}+w_{k}^{s} S_{k}
$$

Second, following Venables (1994) we combine the free entry condition, the expression for the price index and the markup pricing rule to express the share of exporting firms as follows:

$$
\left(\frac{N_{k k}}{N_{l k}}\right)^{\frac{\sigma-\varepsilon}{\sigma-1}}=\frac{\frac{C B_{l k}}{\varphi_{l}}}{\frac{C B_{k k}}{\varphi_{k}}} \frac{f_{l k}}{f_{k k}} \frac{\sum_{v=s, u} z_{k k}^{\alpha_{k}^{v}(\varepsilon-1)}\left(P_{k}^{v}\right)^{\varepsilon} Q_{k}^{v}}{\sum_{v=s, u} z_{l k}^{\alpha_{k}^{v}(\varepsilon-1)}\left(P_{k}^{v}\right)^{\varepsilon} Q_{k}^{v}}\left(\frac{\tau_{l k}\left(z_{l k}^{\frac{1}{\theta}} \frac{C B_{l k}}{\varphi_{l}}+T_{l k}\right)}{\tau_{k k}\left(z_{k k}^{\frac{1}{\theta}} \frac{C B_{k k}}{\varphi_{k}}+T_{k k}\right)}\right)^{\varepsilon-1}
$$

We can now define equilibrium as follows:

Definition 1 Equilibrium in the model is defined by a tuple of vectors in all countries $k$ for all workers $v,\left\{w_{k}^{v}, \alpha_{k}^{v}, Q_{k}^{v}, E_{k}^{v}, P_{k}^{v}\right\}$, in all pairs of countries $k$ and $l,\left\{z_{k l}, C B_{k l}, N_{k l}\right\}$,

\footnotetext{
${ }^{21}$ An explicit expression for $z_{k l}$ is indispensable to solve the model under firm heterogeneity, also when using numerics. The reason is that the free entry condition is expressed as an integral over all active firms. Feenstra and Romalis (2014) do not solve for all endogenous variables in the model and leave the free entry condition aside. Moreover, they can solve explicitly for $z_{k l}$ as there is no role for factor abundance. To be able to solve and simulate the model we thus have to work with identical firms.
} 
and in all pairs of countries $k$ and $l$ for all workers $v,\left\{P_{k l}^{v}\right\}$ and is determined by the following equations in all countries $k$ :

1. The expression for the cost of input bundles in equation (8) to each destination market $l$

2. The expression for expenditure in equation (21)

3. The expression for the price index in equation (22)

4. The expression for the quality elasticity with respect to utility in equation (23)

5. The markup pricing rule in equation (27) to each destination market $l$

6. The FOC for quality in equation (28) to each destination market $l$

7. Labor market equilibrium for skilled and unskilled workers in equations (30) and (31)

8. The income identity in equation (32)

9. The expression for the share of exporting firms in equation (33)

\section{Numerical Analysis of the Theoretical Model}

In this section we numerically solve the extended model with multiple countries as defined in Definition 1 to explore the effect of distance on the skill premium through quality specialization. ${ }^{22}$ We simulate the model with five countries with values for the exogenous variables equal to the values for the largest five countries in our empirical exercise in terms of GDP.

In the simulations we concentrate on the fob price, as our traded goods price data are also fob prices. The fob price can be expressed as a function of the cif price as follows:

$$
p_{k l}^{f o b}=\frac{p_{k l}^{c i f}}{\tau_{k l}}-T_{k l}
$$

We start in the next subsection with a discussion of model calibration. In the following subsections we present simulation results on the role of the extensive margin and the effect of distance on the skill premium. We close this section with robustness checks of the simulation results to variations in parameter values.

\footnotetext{
${ }^{22}$ The GAMS code of the numerical models is available upon request.
} 
Table 2: Baseline values of parameters

\begin{tabular}{|c|c|c|c|}
\hline Parameter & Value & Description & Source \\
\hline$\sigma$ & 6.07 & $\begin{array}{l}\text { Substitution elasticity between varieties } \\
\text { on product market }\end{array}$ & Feenstra and Romalis (2014) \\
\hline$\lambda$ & 0.021 & $\begin{array}{c}\text { Elasticity of taste for quality parameter } \\
\text { with respect to income/capita }\end{array}$ & Feenstra and Romalis (2014) \\
\hline$\theta$ & 0.61 & $\begin{array}{l}\text { Elasticity of marginal costs } \\
\text { with respect to quality }\end{array}$ & Feenstra and Romalis (2014) \\
\hline$\kappa$ & 0.1 & Elasticity of per unit trade costs wrt distance & Feenstra and Romalis (2014) \\
\hline$\varepsilon$ & 1.2 & $\begin{array}{l}\text { Armington substitution elasticity } \\
\text { on the product market }\end{array}$ & Feenstra, et al. (2014) \\
\hline$\rho$ & 1.2 & $\begin{array}{l}\text { Substitution elasticity between skilled } \\
\text { and unskilled labor }\end{array}$ & Hertel, et al. (2012) \\
\hline$f_{k k}$ & 1 & Fixed costs of production & \\
\hline$f_{k l}$ & 1 & Exporting fixed costs & \\
\hline$d_{k l}$ & data & Distance between countries & Clair et al (2004) \\
\hline$\frac{S_{k}}{U_{k}}$ & data & Relative skill abundance & WDI \\
\hline$U_{k}$ & data & Number of unskilled workers & WDI \\
\hline$\varphi_{k}$ & data & Productivity & WDI \\
\hline$\vartheta$ & 0.14 & CES-shifter low-skilled labor & Acemoglu (2003) \\
\hline$\eta$ & 0.79 & $\begin{array}{l}\text { Elasticity of skilled factor intensity } \\
\text { with respect to quality }\end{array}$ & Simulations \\
\hline$\delta$ & 0.05 & $\begin{array}{l}\text { Elasticity of ad valorem trade costs } \\
\text { with respect to distance }\end{array}$ & Simulations \\
\hline
\end{tabular}

\subsection{Calibration}

Table 2 displays the parameter values used in the simulations with the extended model, their description and their source. Model parameters and exogenous variables are on the one hand taken from the literature and the data (section 4.1.1) and on the other hand calibrated to match the regression results with real-world data (section 4.1.2).

\subsubsection{Parameters and Data from the Literature}

We select parameters and data from four different sources. First, for all parameters also appearing in Feenstra and Romalis (2014), we use the values estimated by these scholars. So, the substitution elasticity $\sigma$ between varieties is set at 6.07 ; the elasticity of the taste for quality parameter with respect to income per capita, $\lambda$, is set at 0.021 ; the elasticity of marginal costs with respect to quality, $\theta$, is set equal to 0.61 ; and the elasticity of per unit trade costs with respect to distance is equal to 0.1 .

Second, for some parameters specific to our model and not appearing in Feenstra and Romalis (2014), we select values from the literature. The Armington substitution elasticity $\varepsilon$ is taken from Feenstra, et al. (2014) who come to estimates for the substitution elasticity between domestic and foreign varieties (the 'macro' elasticity) around 1 . We 
choose a value of 1.2 to avoid convergence problems appearing for values of $\varepsilon$ close to 1 . The substitution elasticity between factor inputs not taking into account quality changes is set at 1.2, corresponding with the median value across sectors in Hertel, et al. (2012). Fixed production costs $f_{k k}$ are set at 1 . Bernard, et al. (2007) work with an equally arbitrary value of 0.1 in their simulations, motivating this value with the fact that 0.1 is $5 \%$ of their value for sunk entry costs. Given that we do not have sunk entry costs, we can choose a value of 1 for fixed costs without loss of generality. Following Bernard, et al. (2007) exporter fixed costs are set equal to domestic fixed costs, so that without per unit and ad valorem trade costs selling at home and abroad would be equally attractive.

Third, values for distance $d_{k l}$ and skill abundance $\frac{S_{k}}{U_{k}}$ are set equal to the values in the dataset used for the empirics, using data of the largest five countries in terms of GDP. Domestic distance is set equal to internal distance as reported in Clair et al (2004). The trade literature works increasingly with positive domestic trade costs, see for example Ramondo, et al. (2014). Fourth, the number of unskilled workers $U_{k}$ and productivity $\varphi_{k}$ are determined endogenously, imposing that income and income per capita are equal to the dataset-values used in the empirics. ${ }^{23}$ In a similar way the CES-shifter on lowskilled labor, $\vartheta$, was set at 0.14 in order to generate an average skill premium of 1.6, corresponding with a log skill premium of 0.47 reported in Acemoglu (2003).

\subsubsection{Calibrated Parameters}

We calibrate the elasticity of skilled factor intensity with respect to quality, $\eta$, and the elasticity of iceberg trade costs with respect to distance, $\delta$, such that the estimated elasticities of the fob-price with respect to skill abundance and distance employing data following from model simulations are close to the elasticities estimated with real-world data. In the simulations both distance $d_{k l}$ and skill abundance $\frac{S_{k}}{U_{k}}$ are varied randomly three times each around their respective dataset-values $\overline{d_{k l}}$ and $\frac{\overline{S_{k}}}{U_{k}}$, using $d_{k l}=\overline{d_{k l}}\left(1+\right.$ uniform $(-0.01,0.01)$ and $\frac{S_{k}}{U_{k}}=\overline{\overline{S_{k}}}(1+$ uniform $(-0.01,0.01)$. For each of the nine variations the model is solved thus mimicking variation over time in these variables. Log-fob-prices following from the simulation outcomes are then regressed on log-skill-abundance and log-distance including as in the empirical analysis combined fixed effects for each importer-loop pair. This procedure is repeated 200 times. $^{24}$

Table 3 displays the average estimated coefficients and standard errors of the regres-

\footnotetext{
${ }^{23}$ Income $I_{k}$ is defined as $I_{k}=w_{k s} S_{k}+w_{k u} U_{k}$ and income per capita $i_{k}$ as $i_{k}=\frac{w_{k s} S_{k}+w_{k u} U_{k}}{S_{k}+U_{k}}$.

${ }^{24}$ In all the simulations we check the SOC defined in Appendix A. It is satisfied for all simulations.
} 
Table 3: Estimated elasticities of fob-prices with respect to skill abundance and distance with simulated data

\begin{tabular}{lll}
\hline Variable & Average coefficient & Average standard error \\
\hline Skill abundance $\frac{S_{k}}{U_{k}}$ & 0.0925 & 0.00546 \\
& $(0.0254)$ & $(0.00126)$ \\
Distance $d_{k l}$ & 0.121 & 0.00143 \\
& $(0.00759)$ & $(0.000332)$ \\
\hline
\end{tabular}

The table displays the average coefficient and the average standard error of 200 importer fixed effects regressions of the fob-price on skill abundance and distance, all measured in logs Standard errors of the 200 repititions in parentheses

sions with the simulated data, setting $\eta$ at 0.79 and $\delta$ at $0.05 .{ }^{2526}$ The table shows that the estimated elasticities following from the model simulations are close to the empirically estimated elasticities of 0.095 and 0.094 for skill abundance and 0.116 and 0.127 for distance in respectively the linear and nonlinear specification. The average standard error shows that the coefficients are very significant and the standard errors of the simulations between brackets show that the estimated coefficients do not vary much over the different iterations.

\subsection{The Role of the Extensive Margin}

This subsection explores the effect of the extensive margin on traded goods prices. There is selection into exporting in our model, as only a fraction of all firms export. The fraction of firms exporting is likely to exert an effect on export quality and thus on export prices. If a larger fraction of firms exports, demand for high skilled workers will go up, since exported goods are of higher quality and thus require more high skilled workers. We evaluate the effect of the extensive margin on fob prices with our numerical model randomly varying fixed export costs relative to fixed domestic costs. Column one of table 4 displays the outcomes of regressing fob prices on the extensive margin, defined as the fraction of exporting firms relative to domestic firms, averaged over all export destinations. Skill abundance and distance are also included as regressors and the estimation is repeated 200 times. The table shows that the extensive margin has on average a small negative impact on fob prices. Still, the standard error of the average coefficient between parentheses is

\footnotetext{
${ }^{25}$ In searching for $\delta$ and $\eta, \delta$ was limited between 0 and 0.1 , as the elasticity of ad-valorem trade costs with respect to distance should be smaller than the elasticity of per unit trade costs with respect to distance to generate a Washington-apples effect.

${ }^{26}$ Both per unit and ad valorem trade costs are only a function of distance with respectively elasticities of $\delta=0.05$ and $\eta=0.1$.
} 
Table 4: Estimated elasticities of fob-prices with respect to the extensive margin and fixed export costs

\begin{tabular}{lllll}
\hline Variable & Av. coefficient & Av. Standard error & Av. Coefficient & Av. Standard error \\
\hline Skill abundance $\frac{S_{k}}{U_{k}}$ & 0.0922 & 0.00562 & 0.0930 & 0.00528 \\
& $(0.0376)$ & $(0.00252)$ & $(0.0237)$ & $(0.00120)$ \\
Distance $d_{k l}$ & 0.123 & 0.00117 & 0.122 & 0.00138 \\
Extensive margin $e m_{k}$ & $(0.00120)$ & $(0.000412)$ & $(0.0678)$ & $(0.000316)$ \\
& -0.00465 & 0.00541 & & \\
Export fixed costs $\frac{f_{k l}}{f_{k k}}$ & $(0.0534)$ & $(0.00527)$ & & 0.401 \\
& & & -0.0304 & $(0.0983)$ \\
\hline
\end{tabular}

The table displays the average coefficient and the average standard error of 200 fixed effects regressions of the fob-price on skill abundance, distance and the extensive margin, all measured in logs.

The extensive margin is defined as the share of exporting firms relative to domestic firms. Export fixed costs is defined as export fixed costs divided by domestic fixed costs, both averaged over all trading partners.

Standard errors of the 200 repititions in parentheses

large, indicating that the coefficient varies hugely over the 200 iterations. Therefore, we can conclude that the extensive margin does not have a significant impact on traded goods prices in our model. In column two we also examine the effect of exporting fixed costs relative to domestic fixed costs. Also this variable does not have a significant impact on traded goods prices.

\subsection{Effect of Distance on the Skill Premium}

In this subsection we study the effect of distance on the skill premium. There is both a supply-side and demand-side effect. Since distance has a stronger effect on per unit than on ad valorem trade costs, an increase in distance makes the Washington apples effect stronger. Therefore firms raise the quality of exported goods. As a result the relative demand for skilled labor rises and therefore the nominal skill premium, representing the supply-side effect. Since quality is more important for higher income high-skilled workers, the increase in quality leads to a stronger decrease in the quality adjusted price index for the high-skilled, a demand side effect. In table 5 we display the estimated elasticities of the skill premium with respect to skill abundance and average distance of each country vis-a-vis all its trading partners employing the outcomes of model simulations repeated 200 times based on the baseline parameter values. We display the average elasticity of the nominal skill premium, $\frac{w^{s}}{w^{u}}$, reflecting the supply-side effect, of the quality-adjusted price ratio, $\frac{P^{u}}{P^{s}}$, reflecting the demand-side effect, and of real skill premium, $\frac{w^{s}}{P^{s}} / \frac{w^{u}}{P^{u}}$, reflecting the overall effect. The table shows that distance has a significant, positive effect on the nominal skill premium, with an elasticity of about 0.023 , which means that a doubling 
of distance of a country vis-a-vis all its trading partners will raise its skill premium by 1.6 percent $\left.\left(2^{0.023}-1\right)\right) .{ }^{27}$ So, our finding provides support for the supply-side effect just described. There are two reasons for the relatively modest effect of distance on the skill premium. First, domestic quality will be adjusted downwards in response to an increase in the relative price of skilled labor. This adjustment limits the initial effect on the skill premium. Second, an increase in distance raises both per unit and ad valorem trade costs, reducing the share of production for the export market and thus reducing the share of goods with high quality.

The table also shows that the quality-adjusted price ratio of low-skilled to high-skilled rises significantly with distance, although the effect is an order smaller than the supply-side effect on the nominal skill premium. This finding provides support for the demand-side effect: a larger distance raises the Washington-apples effect, which in turn raises quality benefiting high-skilled workers more than low-skilled workers. The elasticity of the real skill premium with respect to distance in column 5 is the sum of the elasticities of the nominal skill premium and the price ratio.

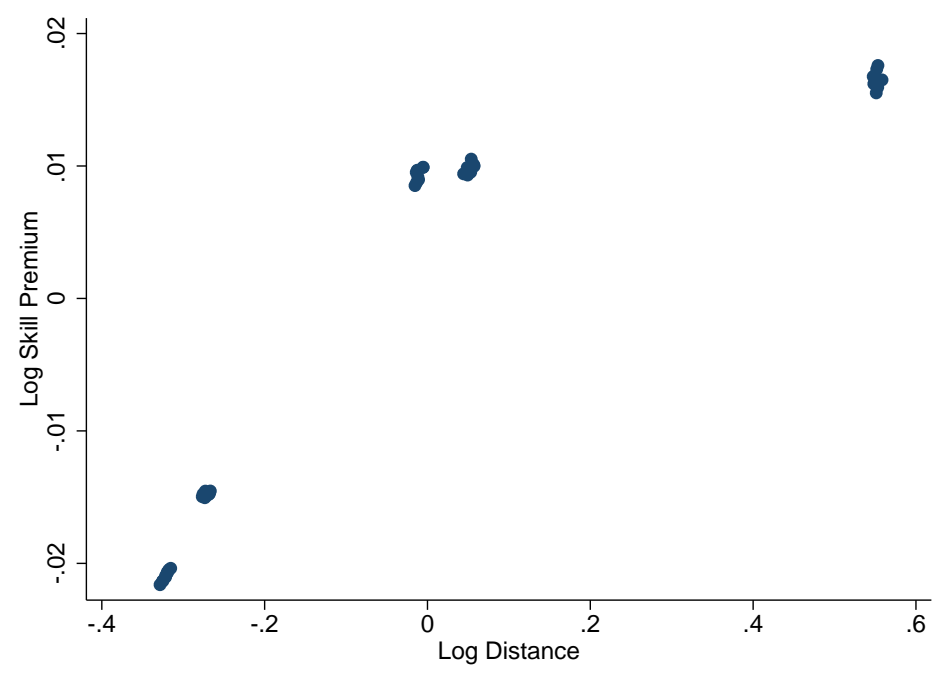

Figure 1: Partial scatter plot of skill premium on distance

Figure 1 shows the partial scatter plot of the skill premium on distance (both measured in logs) following from the partial regression of the skill premium on distance with skill abundance as control variable and importer-repitition fixed effects. The figure shows five sets of scattered points corresponding with observations in the five different countries. The scatter plot shows clearly that there is a positive relation in the model between distance

\footnotetext{
${ }^{27}$ Skill abundance has a strong negative effect on the skill premium, as expected.
} 
Table 5: Estimated elasticities of skill premium with respect to skill abundance and distance with simulated data

\begin{tabular}{lllllll}
\hline Variable & $\frac{w^{s}}{w^{u}}$ & s.e. & $\frac{p^{u}}{p^{s}}$ & s.e. & $\frac{w^{s}}{P^{s}} / \frac{w^{u}}{P^{u}}$ & s.e. \\
\hline Skill abundance $\frac{S_{k}}{U_{k}}$ & -0.797 & 0.00507 & 0.000873 & 0.000437 & -0.797 & 0.00507 \\
& $(0.00318)$ & $(0.000508)$ & $(0.0000114)$ & $(0.0000112)$ & $(0.00300)$ & $(0.000575)$ \\
Distance $d_{k l}$ & 0.0233 & 0.00506 & 0.0000362 & 0.0000114 & 0.0234 & 0.00505 \\
& $(0.0100)$ & $(0.000571)$ & $(0.0000146)$ & $(0.0000112)$ & $(0.0100)$ & $(0.000571)$ \\
\hline
\end{tabular}

The table displays the average coefficient and the average standard error of 200 regressions of the nominal skill premium $\frac{w^{s}}{w^{u}}$ and the price ratio $\frac{p^{u}}{p^{s}}$ on skill abundance and average distance of each country vis-a-vis all its trading partners, all measured in logs.

Standard errors of the 200 repititions in parentheses

and the skill premium.

A reduction of ad valorem trade costs works in the model like an increase in distance, as the elasticity of ad valorem trade costs with respect to distance is smaller than the elasticity of per unit trade costs with respect to distance. So with lower ad valorem trade costs the Washington apples effect becomes stronger raising the skill premium. We summarize the above discussion as follows:

Observation 1 In the model with per unit and ad valorem trade costs and demand for quality varying with income, a reduction in distance raises the real skill premium through a strengthening of the Washington Apples effect.

We perform two additional exercises to get more insight into the effect of trade costs and distance on the skill premium. First we compare the average skill premium in all countries in a situation with actual distance between trading partners and a situation with distance between trading partners set equal to average domestic distance of the five countries. This exercise thus shows what the effect is of neutralizing distance between all trading partners. Increasing distance between trading partners from the domestic level to the actual level leads as expected to an increase in the average skill premium in all countries from 1.31 to 1.66 and the difference is highly significant. Increasing distance for sales in other countries raises the quality of goods sold because of the Washington apples effect and this drives up the relative demand for skilled workers.

Second, we simulate the model two times, first switching off the supply-side mechanism and then the demand-side mechanism by first setting $\eta$ at zero and then setting $\lambda$ at zero. The Washington apples effect creates an effect of distance both through the demand-side as a result of non-homothetic preferences with higher income agents demanding higher quality goods and through the supply-side as a result of non-homothetic technology with quality being skill intensive. We thus assess the relative contribution of demand-side 
Table 6: Estimated elasticities of skill premium with respect to skill abundance and distance with simulated data with $\eta=0$ and $\lambda=0$

\begin{tabular}{|c|c|c|c|c|c|c|}
\hline Variable & $\frac{w^{s}}{w^{u}}$ & s.e. & $\frac{p^{u}}{p^{s}}$ & s.e. & $\frac{w^{s}}{P^{s}} / \frac{w^{u}}{P^{u}}$ & s.e. \\
\hline \multicolumn{7}{|l|}{$\eta=0$} \\
\hline Skill abundance $\frac{S_{k}}{U_{k}}$ & $\begin{array}{l}-0.833 \\
(2.44 e-06)\end{array}$ & $\begin{array}{l}5.42 e-07 \\
(3.04 e-06)\end{array}$ & $\begin{array}{l}-4.51 e-06 \\
(0.000148)\end{array}$ & $\begin{array}{l}0.0000113 \\
(3.51 e-07)\end{array}$ & $\begin{array}{l}-0.833 \\
(0.000148)\end{array}$ & $\begin{array}{l}0.0000116 \\
(2.05 e-06)\end{array}$ \\
\hline Distance $d_{k l}$ & $\begin{array}{l}9.05 e-07 \\
(5.42 e-06)\end{array}$ & $\begin{array}{l}5.39 e-07 \\
(3.02 e-06)\end{array}$ & $\begin{array}{l}0.0000943 \\
(1.14 e-06)\end{array}$ & $\begin{array}{l}0.0000112 \\
(3.57 e-07)\end{array}$ & $\begin{array}{l}0.0000953 \\
(5.65 e-06)\end{array}$ & $\begin{array}{l}0.0000116 \\
(2.04 e-06)\end{array}$ \\
\hline \multicolumn{7}{|l|}{$\lambda=0$} \\
\hline Skill abundance $\frac{S_{k}}{U_{k}}$ & $\begin{array}{l}-0.797 \\
(0.00440)\end{array}$ & $\begin{array}{l}0.00521 \\
(0.000744)\end{array}$ & $\begin{array}{l}6.90 e-14 \\
(4.88 e-13)\end{array}$ & $\begin{array}{l}8.46 e-14 \\
(5.98 e-13)\end{array}$ & $\begin{array}{l}-0.797 \\
(0.00440)\end{array}$ & $\begin{array}{l}0.00521 \\
(0.000744)\end{array}$ \\
\hline Distance $d_{k l}$ & $\begin{array}{l}0.0238 \\
(0.00914)\end{array}$ & $\begin{array}{l}0.00519 \\
(0.000741)\end{array}$ & $\begin{array}{l}-1.51 e-13 \\
(1.07 e-12)\end{array}$ & $\begin{array}{l}8.44 e-14 \\
(5.97 e-13)\end{array}$ & $\begin{array}{l}0.0238 \\
(0.00914)\end{array}$ & $\begin{array}{l}0.00519 \\
(0.000741)\end{array}$ \\
\hline
\end{tabular}

The table displays the average coefficient and the average standard error of 50 regressions of the nominal skill premium $\frac{w^{s}}{w^{u}}$ and the price ratio $\frac{p^{u}}{p^{s}}$ on skill abundance and average distance of each country vis-a-vis all its trading partners, all measured in logs, for respectively $\eta=0$ and $\lambda=0$ Standard errors of the 50 repititions in parentheses

and supply-side forces by switching off respectively non-homothetic technology and nonhomothetic preferences. Table 6 displays the results. The results are as expected. If we set $\eta$ at zero, the effect of distance on the nominal skill premium becomes zero and the supply-side effect disappears. With $\eta$ equal to zero, skill intensity of production is not related to quality and hence the increasing quality as a result of the Washington apples effect does not affect the skill premium. Instead the small demand-side effect on the price ratio remains in place. If instead we set $\lambda$ at zero, the effect of distance on the price ratio becomes zero and the demand-side effect disappears. The quality-adjusted price is the same for both income groups with $\lambda$ equal to zero and henceforth the Washington apples effect has no differential impact on the quality-adjusted prices of the two income groups. The supply-side effect on the nominal skill premium instead remains in place.

\subsection{Robustness Checks}

To check the robustness of our simulations, we evaluate the effect of variation in the parameters $\sigma, \lambda, \theta, \kappa, \varepsilon, f_{k l}, f_{k l} / f_{k k}, \eta$ and $\delta$ on the estimated elasticities of both fobprices and the skill premium with respect to distance and skill abundance. We vary these parameters one at a time. Table 7 shows how the elasticities vary with the parameter values. The second column shows the minimum and maximum value of the different parameters in the robustness checks and for comparison the baseline value. The next two columns show the elasticities of the fob price with respect to distance and skill abundance corresponding with the maximum and minimum parameter values. The last column 
displays the elasticities of the real skill premium with respect to distance for the minimum and maximum parameter values. The reported elasticities are averages based upon 50 repititions with the reported parameter values.

We can make the following five observations on the robustness exercises. First, signs of the three elasticities of the export price with respect to skill abundance and distance and of the elasticity of the skill premium with respect to distance always stay the same. Second, the parameters $\lambda, \frac{f_{k l}}{f_{k k}}$ and $f_{k l}$ have only a relatively small impact on the elasticities. So, although the level of fixed costs was set somewhat arbitrary this has almost no effect on the model outcomes. Third, the elasticity of the skill premium with respect to distance, reported in the last columns of 7 , always stays positive but also relatively small. ${ }^{28}$ Fourth, the effect of the substitution elasticity $\sigma$ on the elasticity of the export price with respect to skill abundance is positive but small. The sign of this interaction effect is hence opposite to what we find in the empirics, but like in the empirics where the effect is non-significant, the effect is small. Fifth and finally, the parameters with a relatively strong impact on the elasticity of the export price with respect to skill abundance are $\theta$ and $\eta$. We interpret the influence of these parameters on the elasticities as follows. $\theta$ is an inverse measure of the marginal cost to produce quality. So, at a small $\theta$ it is expensive to produce high quality goods and henceforth a cost advantage to produce high quality goods because of a relative abundance of skilled workers will hardly lead to higher quality goods. A similar intuition holds for the effect of $\eta$ on the elasticity of the export price with respect to skill abundance, which rises with $\eta$.

\section{Concluding Remarks}

In this paper we put forward a theoretical mechanism to explain the finding in Schott (2004) that more skill abundant countries export higher quality, higher priced goods. Factor input bundles are nonhomothetic with higher quality goods requiring relatively more skilled workers. This implies that in skill abundant countries firms have an incentive to produce higher quality goods. With marginal costs rising in quality, higher quality goods also have higher prices. We incorporated this mechanism in a monopolistic competition model of trade adding a role for distance and importer gdp per capita in the determination of traded goods prices implying a Washington-apples effect. We estimated the effect of skill abundance and distance using a dataset with multiple importers and

\footnotetext{
${ }^{28}$ Although not reported, the elasticity of the skill premium with respect to skill abundance hardly varies with parameters values. For the parameter variations explored it oscillates between -0.816 and -0.776 .
} 
Table 7: Simulated elasticities of the traded goods price with respect to distance, skill abundance and exporter gdp per capita and of the skill premium with respect to distance.

\begin{tabular}{llllllllll}
\hline Parameter & \multicolumn{2}{l}{$\begin{array}{l}\text { Parameter } \\
\text { values }\end{array}$} & \multicolumn{3}{c}{$\begin{array}{l}\text { Elasticity } \\
\text { wrt } S / U\end{array}$} & \multicolumn{2}{c}{$\begin{array}{l}\text { Elasticity } p_{x} \\
\text { wrt distance }\end{array}$} & \multicolumn{2}{l}{$\begin{array}{l}\text { Elasticity } w_{s} / w_{u} \\
\text { wrt distance }\end{array}$} \\
\hline & Min & Base & Max & Min & Max & Min & Max & Min & Max \\
\hline$\sigma$ & 3.05 & 6.07 & 6.2 & 0.0258 & 0.0925 & 0.121 & 0.141 & 0.0208 & 0.0233 \\
$\lambda$ & 0.01 & 0.021 & 0.05 & 0.0864 & 0.0979 & 0.121 & 0.124 & 0.0231 & 0.0259 \\
$\theta$ & 0.4 & 0.61 & 0.7 & 0.0212 & 0.122 & 0.119 & 0.136 & 0.0140 & 0.0257 \\
$\kappa$ & 0.05 & 0.1 & 0.25 & 0.0641 & 0.123 & 0.0871 & 0.265 & 0.0199 & 0.0255 \\
$\varepsilon$ & 1.2 & 1.2 & 1.8 & 0.0647 & 0.089 & 0.123 & 0.138 & 0.0232 & 0.0301 \\
$f_{k l}$ & 0.5 & 1 & 2.5 & 0.0765 & 0.0925 & 0.121 & 0.127 & 0.0233 & 0.0246 \\
$f_{k l}$ & 1 & 1 & 2.25 & 0.0876 & 0.0954 & 0.121 & 0.123 & 0.0234 & 0.0220 \\
$f_{k k}$ & 0.6 & 0.8 & 1.4 & 0.112 & 0.643 & 0.117 & 0.121 & 0.0233 & 0.0337 \\
$\delta$ & 0.01 & 0.05 & 0.05 & 0.0671 & 0.0925 & 0.0943 & 0.124 & 0.0227 & 0.0241 \\
\hline
\end{tabular}

exporters containing export unit values as proxy for export prices. We found as expected that traded goods prices rise in the two mentioned variables and used the estimated elasticities to calibrate the parameters of the model. Simulating the impact of changes in distance, we found an effect of distance on the skill premium in our model. Countries at a larger distance from their trading partners display a stronger Washington-apples effect raising the quality of goods sold and bought. Because of the skill-intensity of high-quality goods this raises the nominal skill premium (a supply-side effect) and because of the non-homotheticity of demand this also reduces the relative quality-adjusted price level of high-income, high-skilled workers (a demand-side effect).

\section{References}

Acemoglu, Daren (2003). 'Patterns of Skill Premia.' Review of Economic Studies 70: 199230.

Alchian, Armen A., and William R. Allen (1964). University Economics. Belmont, California: Wadsworth.

Alessandria, G. and J. Kaboski (2011). 'Pricing-to-Market and the Failure of Absolute PPP.' American Economic Journal: Macroeconomics 3(1): 91-127.

Anderson, J. and E. Van Wincoop (2003). 'Gravity with Gravitas: A Solution to the Border Puzzle.' American Economic Review 93: 170-192. 
Baldwin, R. and J. Harrigan (2011). 'Zeros, Quality and Space: Trade Theory and Trade Evidence.' American Economic Journal: Microeconomics 3(2): 60-88.

Bastos, P. and J. Silva (2010). 'The quality of a firm's exports: Where you export to matters.' Journal of International Economics 82(2): 99 -111.

Bekkers, Eddy, Joseph Francois and Miriam Manchin (2012). 'Import Prices, Income, and Inequality.' European Economic Review 56: 848-869.

Bekkers, Eddy (2013). 'Firm Heterogeneity, Endogenous Innovation and Traded Goods Prices.' Mimeo Johannes Kepler University Linz.

Bernard, Andrew B., Stephen J. Redding and Peter K. Schott (2007). 'Comparative Advantage and Heterogeneous Firms.' Review of Economic Studies 74: 31-66.

C. Broda, J. Greenfield and D. Weinstein (2006). 'From Groundnuts to Globalization: A Structural Estimate of Trade and Growth.' NBER Working Paper No. 12512.

Burstein, Ariel and Jonathan Vogel (2012). 'International Trade, Technology, and The Skill Premium.' 2012 Meetin papers 664, Society for Economic Dynamics.

Caron, Justin, Thibault Fally and James R. Markusen (2014). 'Skill Premium and Trade Puzzles: A Solution Linking Production and Preferences.' NBER Working Paper No. 18131.

Caron, Justin, Thibault Fally and James R. Markusen (2014). 'International Trade Puzzles: a Solution Linking Production and Preferences.' Forthcoming Quarterly Journal of Economics.

Clair, G., G. Gaulier, T. Mayer, and S. Zignago (2004). 'Notes on CEPII's distances measures.' CEPII: Paris.

Crozet M., K. Head and T. Mayer (2012). 'Quality sorting and trade: Firm-level evidence for French wine.' Review of Economic Studies 79(2): 609-644.

Dingel, Jonathan I. (2014). 'The Determinants of Quality Specialization.' Mimeo Columbia University.

Fajgelbaum, Pablo, Gene M. Grossman and Elhanan Helpman (2011). 'Income Distribution, Product Quality, and International Trade.' Journal of Political Economy 119(4): 721-765. 
Fajgelbaum, Pablo D. and Amit K. Khandelwal (2014). 'Measuring the Unequal Gains from Trade.' NBER Working Paper No. 20331

Falvey, Rodney E. (1981). 'Commercial Policy and Intra-industry Trade.' Journal of International Economics 11: 495-511.

Feenstra, R.C., P. Luck, M. Obstfeld and K.N. Russ (2014). 'In Search of the Armington Elasticity.' CEPR Discussion Paper 9951.

Robert C. Feenstra and John Romalis (2014). 'International Prices and Endogenous Quality.' Quarterly Journal of Economics 129(2): 477-527.

Ana Cecilia Fieler (2012). 'Quality Differentiation in Trade: Theory and Evidence.' Mimeo University of Pennsylvania.

Flam, H. and E. Helpman (1987). 'Vertical Product Differentiation and North-South Trade.' American Economic Review 77(5): 810-822.

Di Giovanni, Julian and Andrei A. Levchenko (2013). 'Firm Entry, Trade, and Welfare in Zipf's World.' Journal of International Economics 89(2): 283-296.

Görg, H., L. Halpern and B. Muraközy (2010). "Why Do Within Firm-Product Export Prices Differ Across Markets?" Kiel Working Paper No. 1596.

Hallak, J.C. (2006). 'Product Quality and The Direction of Trade.' Journal of International Economics 68: 238-265.

Hallak, J.C. and J. Sivadasan (2010). 'Firms' Exporting Behavior under Quality Constraints.' NBER Working Paper No. 14928.

Harrigan, James, Xiangjun Ma and Victor Shlychkov (2011). 'Export Prices of US Firms.' Mimeo University of Virginia.

Harrigan, James and Ariell Reshef (2011). 'Skill biased heterogeneous firms, trade liberalization, and the skill premium.' Mimeo University of Virginia.

Thomas W. Hertel, Badri Narayanan G. and Robert A. McDougall (2012). 'Behavioral Parameters.' In: Narayanan, G., Badri, Angel Aguiar and Robert McDougall, Eds. 2012. Global Trade, Assistance, and Production: The GTAP 8 Data Base. Center for Global Trade Analysis, Purdue University. 
Hummels, David \& Peter J. Klenow (2005). 'The Variety and Quality of a Nation's Exports.' American Economic Review 95(3): 704-723.

Hsieh, C-T. and P. J. Klenow (2007). 'Relative Prices and Relative Prosperity.' American Economic Review 97(3): 562-585.

David Hummels and Alexandre Skiba (2004). 'Shipping the Good Apples Out? An Empirical Confirmation of the Alchian-Allen Conjecture.' Journal of Political Economy 112(6): 1384-1402.

Hummels, D., V. Lugovskyy (2009). 'International Pricing in a Generalized Model of Ideal Variety.' Journal of Money, Credit and Banking 41(1): 3-33.

Jean, Sebastien (2002). 'International Trade and Firms' Heterogeneity under Monopolistic Competition.' Open Economics Review 13: 291-311.

Krugman, Paul R. (1980). 'Scale Economies, Product Differentiation, and the Pattern of Trade.' American Economic Review 70: 950-959.

Eric Verhoogen and Maurice Kugler (2012). 'Prices, Plant Size, and Product Quality.' Review of Economic Studies 79 (1): 307-339.

Manova, Kalina and Zhiwei Zhang (2012). 'Export Prices across Firms and Destinations.' Quarterly Journal of Economics 127: 379-436.

Matsuyama, Kiminori (2007) 'Beyond Icebergs: Towards a Theory of Biased Globalization.' The Review of Economic Studies 74(1): 237-253

Martin, Julien (2012). 'Markups, Quality, and Transport Costs.' European Economic Review 56: 777-791.

Melitz, Marc J. (2003). 'The Impact of Trade on Intra-Industry Reallocations and Aggregate Industry Productivity,' Econometrica 71 (6): 1695-1725.

Ramondo, Natalia, Andres Rodriguez-Clare and Milagro Saborio-Rodriguez (2014). 'Trade, Domestic Frictions, and Scale Effects.' Mimeo UC-Berkeley.

Schott, Peter K. (2004). 'Across-Product Versus Within-Product Specialization in International Trade.' Quarterly Journal of Economics 119 (2):. 647-678.

Shimomura, Koji (1999). 'A Simple Proof of the Sato Proposition on Non-Homothetic CES Functions, 'Economic Theory 14(2): 501-503. 
Simonovska, Ina (2010). 'Income Differences and Prices of Tradables.' NBER Working Paper No. 16233.

Venables, Anthony J. (1994). 'Integration and The Export Behaviour of Firms - Trade Costs, Trade Volume and Welfare.' Weltwirtschaftliches Archiv 130: 118-132.

Verhoogen, Eric A. (2008). 'Trade, Quality Upgrading and Wage Inequality in the Mexican Manufacturing Sector,' Quarterly Journal of Economics 123(2): 489-530. 


\section{Appendix A Derivations Theoretical Model}

In this appendix we present derivations of some of the equations in the main text in chronological order.

Equations (10) and (11)

Taking first order conditions of the expression for profit in equation (9) with respect to $p_{k l}$ and $\alpha_{k l}$ leads to:

$$
\begin{gathered}
(1-\sigma) z_{k l}^{\sigma-1} p_{k l}^{-\sigma} P_{k l}^{\sigma-\varepsilon} P_{l}^{\varepsilon} I_{l}+\sigma z_{k l}^{\frac{1}{\theta}+\sigma-1} \tau_{k l} p_{k l}^{-\sigma-1} P_{k l}^{\sigma-\varepsilon} P_{l}^{\varepsilon} I_{l} C B_{k l}=0 \\
(\sigma-1) z_{k l}^{\sigma-2} p_{k l}^{1-\sigma} P_{k l}^{\sigma-\varepsilon} P_{l}^{\varepsilon} I_{l}-\left(\frac{1}{\theta}+\sigma-1\right) z_{k l}^{\frac{1}{\theta}+\sigma-2} \tau_{k l} p_{k l}^{-\sigma} P_{k l}^{\sigma-\varepsilon} P_{l}^{\varepsilon} I_{l} C B_{k l} \\
-\left(z_{k l}^{\frac{1}{\theta}+\sigma-1} \tau_{k l} p_{k l}^{-\sigma} P_{k l}^{\sigma-\varepsilon} P_{l}^{\varepsilon} I_{l}+f_{k l}\right) \frac{\partial C B_{k l}}{\partial z_{k l}}=0
\end{gathered}
$$

The first FOC in (A.1) can be rearranged easily into the markup equation in (10) in the main text. Substituting the markup equation into the second FOC in (A.2) leads after some rearranging to equation (11). Substituting the free entry condition into equation (11) then gives:

$$
\frac{p_{k l} q_{k l}}{\sigma}\left(\frac{(\sigma-1) \frac{\theta-1}{\theta}}{z_{k l}}-\frac{\sigma}{C B_{k l}} \frac{\partial C B}{\partial z_{k l}}\right)=0
$$

Subsituting equation (13) into equation (A.3) leads to equation (11) in the main text.

Equation (15)

Substituting the expression for $C B_{k l}$ in equation (8) into equation (11) and rearranging leads to:

$$
\frac{\frac{\sigma-1}{\sigma} \frac{\theta-1}{\theta}(1-\rho)}{\eta}=\frac{\left(z_{k l}^{\eta} w_{k}^{s}\right)^{1-\rho}}{\left(z_{k l}^{\eta} w_{k}^{s}\right)^{1-\rho}+\left(w_{k}^{u}\right)^{1-\rho}}
$$

Dividing by $\left(w_{k}^{s}\right)^{1-\rho}$ in the numerator and denominator on the RHS and defining $\zeta$ as $\zeta=\frac{\sigma-1}{\sigma} \frac{\theta-1}{\theta} \frac{1}{\eta}$ gives:

$$
\zeta=\frac{\left(z_{k l}^{\eta}\right)^{1-\rho}}{\left(z_{k l}^{\eta}\right)^{1-\rho}+\left(\frac{w_{k}^{u}}{w_{k}^{s}}\right)^{1-\rho}}
$$

Rearranging equation (A.5) leads to the following equation, which is equivalent to equation (15) in the main text:

$$
\frac{w_{k}^{u}}{w_{k}^{s}}=z_{k l}^{\eta}\left(\frac{1-\zeta}{\zeta}\right)^{\frac{1}{1-\rho}}
$$

$\widehat{C B_{k l}}=0$ in equation (20) 
We rewrite the expression for the cost of input bundles in equation (8) first as follows:

$$
C B_{k l}=w_{k}^{u}\left(\left(z_{k l}^{\eta} \frac{w_{k}^{s}}{w_{k}^{u}}\right)^{1-\rho}+1\right)^{\frac{1}{1-\rho}}
$$

Log differentiating with respect to $z_{k l}^{\eta}$ and the relative wage $\frac{w_{k}^{s}}{w_{k}^{u}}$ keeping the unskilled wage $w_{k}^{u}$ constant, reflecting that we could choose this price as numeraire, gives:

$$
\widehat{C B_{k l}}=\frac{\left(z_{k l}^{\eta} \frac{w_{k}^{s}}{w_{k}^{u}}\right)^{1-\rho}}{\left(z_{k l}^{\eta} \frac{w_{k}^{s}}{w_{k}^{u}}\right)^{1-\rho}+1} \frac{\widehat{w_{k s}}}{w_{k u}}+\frac{\left(z_{k l}^{\eta} \frac{w_{k}^{s}}{w_{k}^{u}}\right)^{1-\rho}}{\left(z_{k l}^{\eta} \frac{w_{k}^{s}}{w_{k}^{u}}\right)^{1-\rho}+1} \widehat{z_{k l}^{\eta}}
$$

Variables with a hat indicate relative changes. We can express $\widehat{z_{k l}^{\eta}}$ as a function of $\frac{\widehat{w_{k}^{s}}}{w_{k}^{u}}$ by $\log$ differentiating equation (15):

$$
\widehat{z_{k l}^{\eta}}=-\frac{\widehat{w_{k}^{s}}}{w_{k}^{u}}
$$

Substituting (A.8) into equation (A.7) makes immediately clear that $\widehat{C B_{k l}}=0$.

Equation (28)

Because there are two income groups we cannot work with quality-adjusted price and quantity like Feenstra and Romalis (2014). Using the expressions for demand and costs in the extended model in respectively equations (24) and (25), profit for sales from $k$ to $l$ can be expressed as follows: ${ }^{29}$

$$
\begin{aligned}
\pi_{k} & =p_{k l}^{1-\sigma} \sum_{v=s, u} z_{k l}^{\alpha_{l}^{v}(\sigma-1)}\left(P_{k l}^{v}\right)^{\sigma-\varepsilon}\left(P_{l}^{v}\right)^{\varepsilon} Q_{l}^{v} \\
& -\tau_{k l}\left(z_{k l}^{\frac{1}{\theta}} \frac{C B_{k l}}{\varphi_{k}}+T_{k l}\right) p_{k l}^{-\sigma} \sum_{v=s, u} z_{k l}^{\alpha_{l}^{v}(\sigma-1)}\left(P_{k l}^{v}\right)^{\sigma-\varepsilon}\left(P_{l}^{v}\right)^{\varepsilon} Q_{l}^{v}-f_{k l} \frac{C B_{k l}}{\varphi_{k}}
\end{aligned}
$$

Taking first order conditions of the expression for profit in equation (A.9) with respect to

\footnotetext{
${ }^{29} \mathrm{An}$ extended version of the following derivation is provided in a supplementary appendix available upon request.
} 
$p_{k l}$ and $z_{k l}$ gives:

$$
\begin{aligned}
0 & =(1-\sigma) p_{k l}^{-\sigma} \sum_{v=s, u} z_{l k}^{\alpha_{k}^{v}(\sigma-1)}\left(P_{l k}^{v}\right)^{\sigma-\varepsilon}\left(P_{k}^{v}\right)^{\varepsilon} Q_{k}^{v} \\
& +\sigma \tau_{k l}\left(\frac{C B_{k l}}{\varphi_{k}} z_{k l}^{\frac{1}{\theta}}+T_{k l}\right) p_{k l}^{-\sigma-1} \sum_{v=s, u} z_{l k}(\omega)^{\alpha_{k}^{v}(\sigma-1)}\left(P_{l k}^{v}\right)^{\sigma-\varepsilon}\left(P_{k}^{v}\right)^{\varepsilon} Q_{k}^{v} \\
0 & =(\sigma-1) p_{k l}^{1-\sigma} \sum_{v=s, u} \alpha_{l}^{v} z_{k l}^{\alpha_{l}^{v}(\sigma-1)-1}\left(P_{k l}^{v}\right)^{\sigma-\varepsilon}\left(P_{l}^{v}\right)^{\varepsilon} Q_{l}^{v} \\
& -(\sigma-1)\left(\tau_{k l}\left(z_{k l}^{\frac{1}{\theta}} \frac{C B_{k l}}{\varphi_{k}}+T_{k l}\right)\right) p_{k l}^{-\sigma} \sum_{v=s, u} \alpha_{l}^{v} z_{k l}^{\alpha_{l}^{v}(\sigma-1)-1}\left(P_{k l}^{v}\right)^{\sigma-\varepsilon}\left(P_{l}^{v}\right)^{\varepsilon} Q_{l}^{v} \\
& -\frac{1}{\theta} \tau_{k l} z_{k l}^{\frac{1}{\theta}-1} p_{k l}^{-\sigma} \sum_{v=s, u} z_{k l}^{\alpha_{l}^{v}(\sigma-1)}\left(P_{k l}^{v}\right)^{\sigma-\varepsilon}\left(P_{l}^{v}\right)^{\varepsilon} Q_{l}^{v} \frac{C B_{k l}}{\varphi_{k}} \\
& +\left(\tau_{k l} p_{k l}^{-\sigma} \sum_{v=s, u} z_{k l}^{\alpha_{l}^{v}(\sigma-1)}\left(P_{k l}^{v}\right)^{\sigma-\varepsilon}\left(P_{l}^{v}\right)^{\varepsilon} Q_{l}^{v}+f_{k l}\right) \frac{1}{\varphi_{k}} \frac{\partial C B}{\partial z_{k l}}
\end{aligned}
$$

The first FOC in (A.10) can be easily rearranged into the markup equation in (27) in the main text. Substituting the markup equation and the expressions for revenues $p_{k l} q_{k l}$ and $p_{k l} q_{k l}^{v}$ into the second FOC, equation (A.11), leads after rearranging to:

$0=\sum_{v=s, u} \frac{p_{k l} q_{k l}^{v}}{\sigma}\left(\frac{\alpha_{l}^{v}(\sigma-1)}{z_{k l}}-\frac{\frac{\sigma-1}{\theta} z_{k l}^{\frac{1}{\theta}-1} \frac{C B_{k l}}{\varphi_{k}}}{z_{k l}^{\frac{1}{\theta}} \frac{C B_{k l}}{\varphi_{k}}+T_{k l}}\right)+\left(\frac{p_{k l} q_{k l}}{\sigma} \frac{z_{k l}^{\frac{1}{\theta}}}{z_{k l}^{\frac{1}{\theta}} \frac{C B_{k l}}{\varphi_{k}}+T_{k l}}(\sigma-1)+f_{k l}\right) \frac{1}{\varphi_{k}} \frac{\partial C B}{\partial z_{k l}}$

As a next step we substitute the FE, $p_{k l} q_{k l}=\frac{\sigma f_{k l} C B_{k l}}{\varphi_{k}}$, giving:

$$
0=\sum_{v=s, u} \frac{p_{k l} q_{k l}^{v}}{\sigma}\left(\frac{\alpha_{l}^{v}(\sigma-1)}{z_{k l}}-\frac{\frac{\sigma-1}{\theta} z_{k l}^{\frac{1}{\theta}-1} \frac{C B_{k l}}{\varphi_{k}}}{z_{k l}^{\frac{1}{\theta}} \frac{C B_{k l}}{\varphi_{k}}+T_{k l}}+\left(\frac{z_{k l}^{\frac{1}{\theta}}(\sigma-1)}{z_{k l}^{\frac{1}{\theta}} \frac{C B_{k l}}{\varphi_{k}}+T_{k l}}+\frac{1}{\frac{C B_{k l}}{\varphi_{k}}}\right) \frac{1}{\varphi_{k}} \frac{\partial C B}{\partial z_{k l}}\right)
$$

Subsituting the expression for the derivative of $C B$ with respect to $z_{k l}$, equation (13), into equation (A.13) leads after rearranging to:

$$
0=\frac{p_{k l} q_{k l}}{\sigma}\left(\sum_{v=s, u} \frac{p_{k l} q_{k l}^{v}}{p_{k l} q_{k l}} \frac{(\sigma-1) \alpha_{l}^{v}}{z_{k l}}-\frac{\frac{\sigma-1}{\theta} z_{k l}^{\frac{1}{\theta}-1} \frac{C B_{k l}}{\varphi_{k}}}{z_{k l}^{\frac{1}{\theta}} \frac{C B_{k l}}{\varphi_{k}}+T_{k l}}+\left(\frac{\sigma \frac{C B_{k l}}{\varphi_{k}} z_{k l}^{\frac{1}{\theta}}+T_{k l}}{\frac{C B_{k l}}{\varphi_{k}} z_{k l}^{\frac{1}{\theta}}+T_{k l}}\right) \frac{\eta\left(z_{k l}^{\eta} w_{k}^{s}\right)^{1-\rho}}{z_{k l} C B_{k l}^{1-\rho}}\right)
$$

Dropping $\frac{p_{k l} q_{k l}}{\sigma}$ and rearranging gives the FOC in equation (28) in the main text.

Second Order Condition (SOC) for quality $z_{k l}$ 
The derivative of $\pi_{k l}$ with respect to $z_{k l}$ in equation (14) is rewritten slightly:

$$
\frac{\partial \pi_{k l}}{\partial z_{k l}}=\frac{1}{z_{k l}}\left((\sigma-1) \frac{\theta-1}{\theta}-\sigma \eta \frac{\left(z_{k l}^{\eta} w_{k}^{s}\right)^{1-\rho}}{\left(z_{k l}^{\eta} w_{k}^{s}\right)^{1-\rho}+\left(w_{k}^{u}\right)^{1-\rho}}\right)
$$

Since the term between brackets is zero in the optimum, we only have to differentiate the terms between brackets with respect to $z_{k l}$ to derive the SOC:

$$
\frac{\partial^{2} \pi_{k l}}{\partial z_{k l}^{2}}=-\sigma \eta \frac{\left(z_{k l}^{\eta} w_{k}^{s}\right)^{1-\rho}}{\left(z_{k l}^{\eta} w_{k}^{s}\right)^{1-\rho}+\left(w_{k}^{u}\right)^{1-\rho}} \frac{(1-\rho) \eta}{z_{k l}}+\sigma \eta \frac{\eta\left(z_{k l}^{\eta} w_{k}^{s}\right)^{1-\rho}\left(z_{k l}^{\eta} w_{k}^{s}\right)^{1-\rho}}{\left(\left(z_{k l}^{\eta} w_{k}^{s}\right)^{1-\rho}+\left(w_{k}^{u}\right)^{1-\rho}\right)^{2}} \frac{(1-\rho) \eta}{z_{k l}}
$$

Rearranging leads to:

$$
\frac{\partial^{2} \pi_{k l}}{\partial z_{k l}^{2}}=-\sigma(1-\rho) \eta^{2} \frac{1}{z_{k l}} \frac{\left(z_{k l}^{\eta} w_{k}^{s}\right)^{1-\rho}\left(w_{k}^{u}\right)^{1-\rho}}{\left(\left(z_{k l}^{\eta} w_{k}^{s}\right)^{1-\rho}+\left(w_{k}^{u}\right)^{1-\rho}\right)^{2}}
$$

So, the SOC is satisfied if $\rho<1$.

To derive the SOC in the extended model, we rewrite the FOC in equation (28) as follows:

$$
\frac{\partial \pi_{k l}}{\partial z_{k l}}=-\frac{1-\theta \sum_{v=S, U} \chi_{k l}^{v} \alpha_{l}^{v}}{\theta} \frac{C B_{k l}}{\varphi_{k}} z_{k l}^{\frac{1}{\theta}}+\sum_{v=s, u} s_{k l}^{v} \alpha_{l}^{v} T_{k l}-\left(\frac{\sigma \frac{C B_{k l}}{\varphi_{k}} z_{k l}^{\frac{1}{\theta}}+T_{k l}}{\sigma-1}\right) \eta \frac{\left(z_{k l}^{\eta} w_{k}^{s}\right)^{1-\rho}}{\left(z_{k l}^{\eta} w_{k}^{s}\right)^{1-\rho}+\left(w_{k}^{u}\right)^{1-\rho}}
$$

Differentiating equation (A.17) with respect to $z_{k l}$ gives after rearranging:

$$
\begin{aligned}
\frac{\partial^{2} \pi_{k l}}{\partial z_{k l}^{2}} & =-\left(\left(\frac{1-\theta \sum_{v=S, U} \chi_{k l}^{v} \alpha_{l}^{v}}{\theta}+\frac{\sigma}{\sigma-1}\right) \frac{C B_{k l}}{\varphi_{k}} z_{k l}^{\frac{1}{\theta}}+\left(\frac{\sigma \frac{C B_{k l}}{\varphi_{k}} z_{k l}^{\frac{1}{\theta}}+T_{k l}}{\sigma-1}\right) \eta(1-\rho) \frac{\left(w_{k}^{u}\right)^{1-\rho}}{C B_{k l}^{1-\rho}}\right) * \\
& \frac{\eta\left(z_{k l}^{\eta} w_{k}^{s}\right)^{1-\rho}}{C B_{k l}^{1-\rho} z_{k l}}+\sum_{v=s, u}\left(\chi_{k l}^{v}\left(\frac{\alpha_{k l}^{v}(\sigma-1)}{z_{k l}}-\sum_{w=s, u} \frac{\alpha_{k l}^{w}(\sigma-1)}{z_{k l}} s_{k l}^{w}\right)\right) \alpha_{l}^{v}\left(z_{k l}^{\frac{1}{\theta}} \frac{C B_{k l}}{\varphi_{k}}+T_{k l}\right) \\
& -\left(\frac{1-\theta \sum_{v=S, U} \chi_{k l}^{v} \alpha_{l}^{v}}{\theta}+\frac{\sigma}{\sigma-1}\right) \frac{C B_{k l}}{\varphi_{k}} \frac{1}{\theta} z_{k l}^{\frac{1}{\theta}-1}
\end{aligned}
$$

We calculate this second derivative in the simulations finding that it is always satisfied.

Equations (30) and (31)

Differentiating the cost function in equation (25) with respect to $w_{k}^{s}$ and summing 
over the firms $N_{k l}$ gives:

$$
S_{k}=\frac{\partial C_{k}\left(z_{k k}, z_{k l}, w_{k}^{s}, w_{k}^{u}\right)}{\partial w_{k}^{s}}=\sum_{l=1}^{K} N_{k l}\left(\tau_{k l} \frac{z_{k l}^{\frac{1}{\theta}}}{\varphi_{k}} q_{k l}+\frac{f_{k l}}{\varphi_{k}}\right) C B_{k l}^{\rho}\left(z_{k l}^{\eta}\right)^{1-\rho}\left(w_{k}^{s}\right)^{-\rho}
$$

The free entry condition, $p_{k l} q_{k l}=\frac{C B_{k l}}{\varphi_{k}} \sigma f_{k l}$, can be solved for $q_{k l}$ applying the pricing equation in (27):

$$
q_{k l}=\frac{\sigma \frac{C B_{k l}}{\varphi_{k}} f_{k l}}{p_{k l}}=\frac{\sigma \frac{C B_{k l}}{\varphi_{k}} f_{k l}}{\frac{\sigma}{\sigma-1} \tau_{k l}\left(z_{k l}^{\frac{1}{\theta}} \frac{C B_{k l}}{\varphi_{k}}+T_{k l}\right)}=\frac{(\sigma-1) \frac{C B_{k l}}{\varphi_{k}} f_{k l}}{\tau_{k l}\left(z_{k l}^{\frac{1}{\theta}} \frac{C B_{k l}}{\varphi_{k}}+T_{k l}\right)}
$$

Substituting (A.20) into (A.19) and rearranging leads to equation (30) in the main text.

Equation (33)

We follow the approach in Venables (1994) to determine the share of exporting firms $N_{l k} / N_{k k}$ from the free entry condition and the definitions of the price indexes. We can write the free entry condition as follows:

$$
q_{l k}=p_{l k}^{-\sigma} \sum_{v=s, u} z_{l k}^{\alpha_{k}^{v}(\sigma-1)}\left(P_{l k}^{v}\right)^{\sigma-\varepsilon}\left(P_{k}^{v}\right)^{\varepsilon} Q_{k}^{v}=\frac{\frac{C B_{l k}}{\varphi_{l}} f_{l k}}{p_{l k}-\tau_{l k}\left(z_{l k}^{\frac{1}{\theta}} \frac{C B_{l k}}{\varphi_{l}}+T_{l k}\right)}
$$

Substituting the markup rule in equation (27) on the RHS and LHS leads to:

$$
\left(\frac{\sigma}{\sigma-1}\right)^{-\sigma} \sum_{v=s, u} z_{l k}^{\alpha_{k}^{v}(\sigma-1)}\left(P_{l k}^{v}\right)^{\sigma-\varepsilon}\left(P_{k}^{v}\right)^{\varepsilon} Q_{k}^{v}=\frac{(\sigma-1) \frac{C B_{l k}}{\varphi_{l}} f_{l k}}{\left(\tau_{l k}\left(z_{l k}^{\frac{1}{\theta}} \frac{C B_{l k}}{\varphi_{l}}+T_{l k}\right)\right)^{1-\sigma}}
$$

Next, we divide the domestic by the importing FE in equation (A.22):

$$
\frac{\sum_{v=s, u} z_{l k}^{\alpha_{k}^{v}(\sigma-1)}\left(P_{l k}^{v}\right)^{\sigma-\varepsilon}\left(P_{k}^{v}\right)^{\varepsilon} Q_{k}^{v}}{\sum_{v=s, u} z_{k k} \alpha_{k}^{v}(\sigma-1)\left(P_{k k}^{v}\right)^{\sigma-\varepsilon}\left(P_{k}^{v}\right)^{\varepsilon} Q_{k}^{v}}=\frac{\frac{C B_{l k}}{\varphi_{l}}}{\frac{C B_{k k}}{\varphi_{k}}} \frac{f_{l k}}{f_{k k}}\left(\frac{\tau_{l k}\left(z_{l k}^{\frac{1}{\theta}} \frac{C B_{l k}}{\varphi_{l}}+T_{l k}\right)}{\tau_{k k}\left(z_{k k}^{\frac{1}{\theta}} \frac{C B_{k k}}{\varphi_{k}}+T_{k k}\right)}\right)^{\sigma-1}
$$

As a next step, we express the price index as a function of the number of varieties:

$$
P_{l k}^{v}=N_{l k}^{\frac{1}{1-\sigma}} z_{l k}^{-\alpha_{k}^{v}} \frac{\sigma}{\sigma-1} \tau_{l k}\left(z_{l k}^{\frac{1}{\theta}} \frac{C B_{l k}}{\varphi_{l}}+T_{l k}\right)
$$


Substituting equation (A.24) into equation (A.23) and rearranging leads to equation (33) in the main text.

$$
\left(\frac{N_{k k}}{N_{l k}}\right)^{\frac{\sigma-\varepsilon}{\sigma-1}}=\frac{\frac{C B_{l k}}{\varphi_{l}}}{\frac{C B_{k k}}{\varphi_{k}}} \frac{f_{l k}}{f_{k k}} \frac{\sum_{v=s, u} z_{k k}^{\alpha_{k}^{v}(\varepsilon-1)}\left(P_{k}^{v}\right)^{\varepsilon} Q_{k}^{v}}{\sum_{v=s, u} z_{l k}^{\alpha_{k}^{v}(\varepsilon-1)}\left(P_{k}^{v}\right)^{\varepsilon} Q_{k}^{v}}\left(\frac{\tau_{l k}\left(z_{l k}^{\frac{1}{\theta}} \frac{C B_{l k}}{\varphi_{l}}+T_{l k}\right)}{\tau_{k k}\left(z_{k k}^{\frac{1}{\theta}} \frac{C B_{k k}}{\varphi_{k}}+T_{k k}\right)}\right)^{\varepsilon-1}
$$




\section{Appendix B Comparison of Our Results with Schott (2004)}

In this Appendix we further explore the differences between our results on skill abundance and the estimation results in Schott (2004). Our estimated coefficients on relative skill abundance are smaller in all specifications than the coefficients presented in Schott (2004). Schott (2004) finds a coefficient of 0.501 on skill abundance (table 5 in Schott (2004)), whereas our estimate varies between 0.057 and 0.095 thus being almost a factor 10 smaller in some of the specifications (in both estimates the variables are in logs). ${ }^{30}$

In the first column of Table 8 we replicate Schott's specification using our data, restricting the sample of importers to the USA as Schott (2004) did and using Schott's measure of skill abundance, the share of skilled workers among all workers. The coefficient is somewhat smaller than that found by Schott (2004), although the difference is small. In the next column (column 2) we extend the sample to include all importers from our dataset and keep on using Schott's measure of skill abundance. The coefficient again becomes somewhat smaller, indicating that restricting the sample to only the USA as importer leads to a higher impact of exporter skill abundance on exported goods prices.

In the next specification we rerun the regression again restricting the sample to only the USA as importer, but with our measure of skill abundance. While Schott (2004) measures skill abundance as the share of skilled workers in total workers, we follow our theoretical model and measure skill abundance as the share of skilled to unskilled workers. Given this definition, our coefficient is expected to be smaller (since the number of skilled workers divided by the number of unskilled workers will be larger than the number of skilled divided by the number of unskilled plus skilled workers, the coefficient of the latter should be bigger). Indeed, this is what we see in column 3, with the coefficient of skill abundance using our definition being less than half of that using Schott (2004) definition.

Column 4 and 5 explore further how the coefficient of skill abundance changes as we include our control variables. The coefficient gets smaller as we introduce the control variables, and again it is even smaller when all the importers are not restricted to the USA. The final column displays results using our measure of skill abundance, limiting the sample to the USA as the only importer and including control variables. This specification results in an even lower coefficient on skill abundance.

\footnotetext{
${ }^{30}$ The coefficient on GDP per capita in our estimates is similar to Schott (2004) who finds a coefficient of 0.13 , whereas we find a coefficient 0.15 in the linear specification and a marginal effect of 0.19 in the non linear specification.
} 
Table 8: Comparison of Schott (2004) and our results

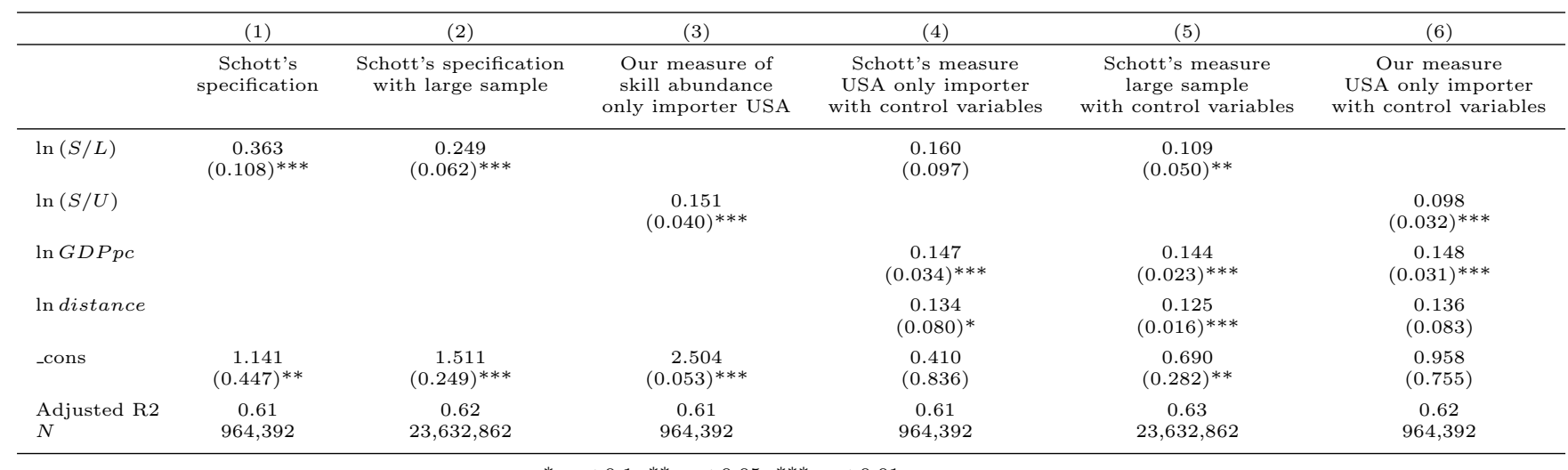

\[ p<0.1 ; * *<0.05 ; * * p<0.01 \]
Importer-product-time fixed effects are included in all specifications with more than one importer,

and product-time fixed effects in specifications with USA as the only importer.Standard errors are clustered by exporters. $\ln (S / L)$ is the exporter's skill abundance defined as the log of the ratio of skilled to total workers. $\ln (S / U)$ is the exporter's skill abundance defined as the $\log$ of the ratio of skilled to unskilled workers. In distance is the log of distance between the exporter and importer country capitals. $\ln G D P p c$ is the log of GDP per capita of the exporter country in 1000 dollars.

Thus these results show that there are three factors which all lead to a smaller coefficient in our results. Extending the number of importers, including other control variables, and using our measure of skill abundance all lead to lower coefficients of exporter skill abundance on exported goods prices. 


\section{Appendix C Descriptive Statistics and List of Coun- tries}

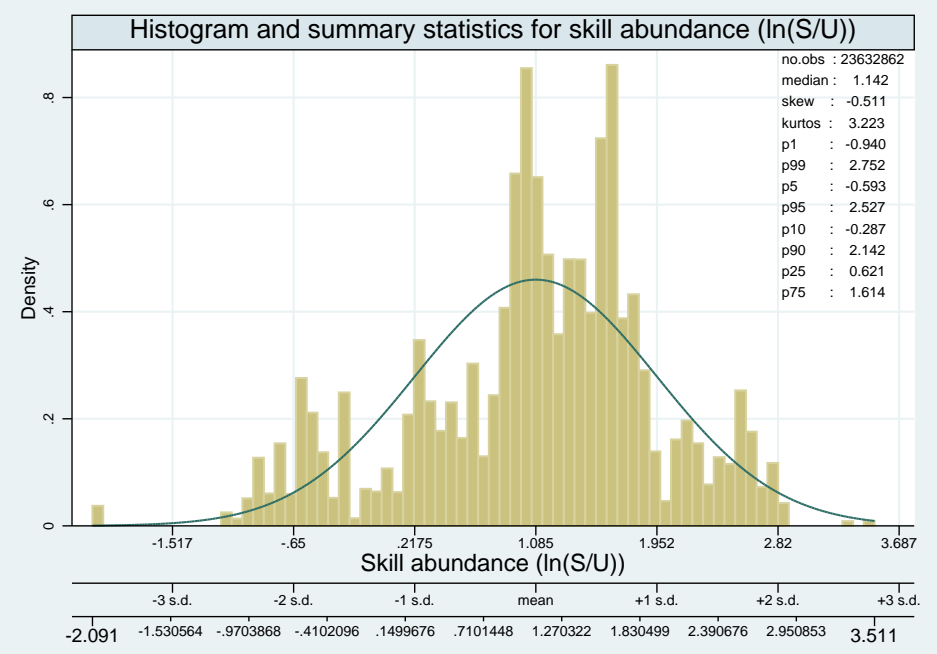

Figure 2: Histogram and summary statistics for relative skill abundance

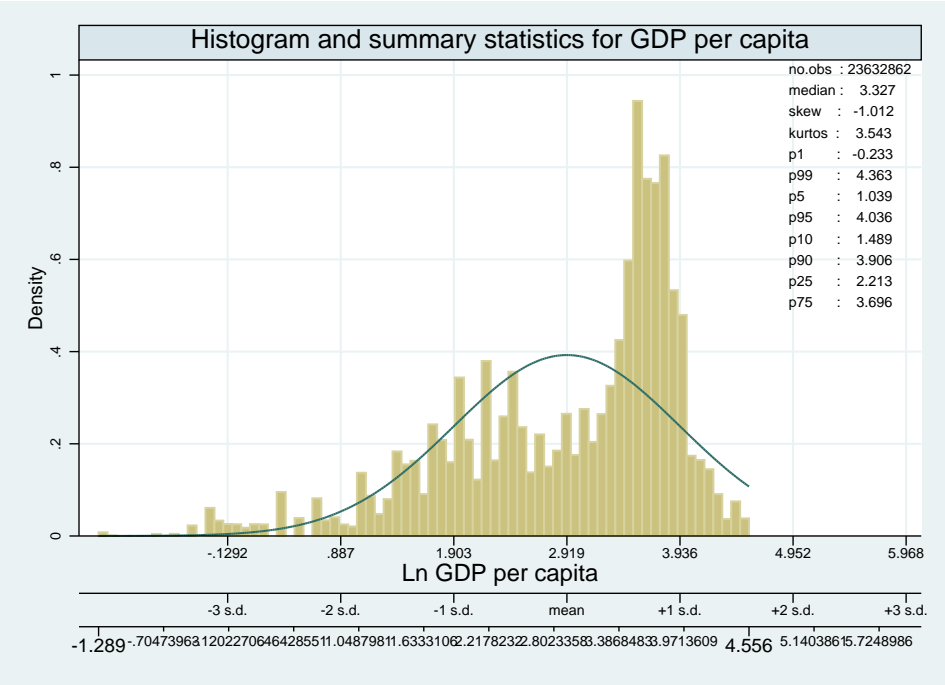

Figure 3: Histogram and summary statistics for GDP per capita 


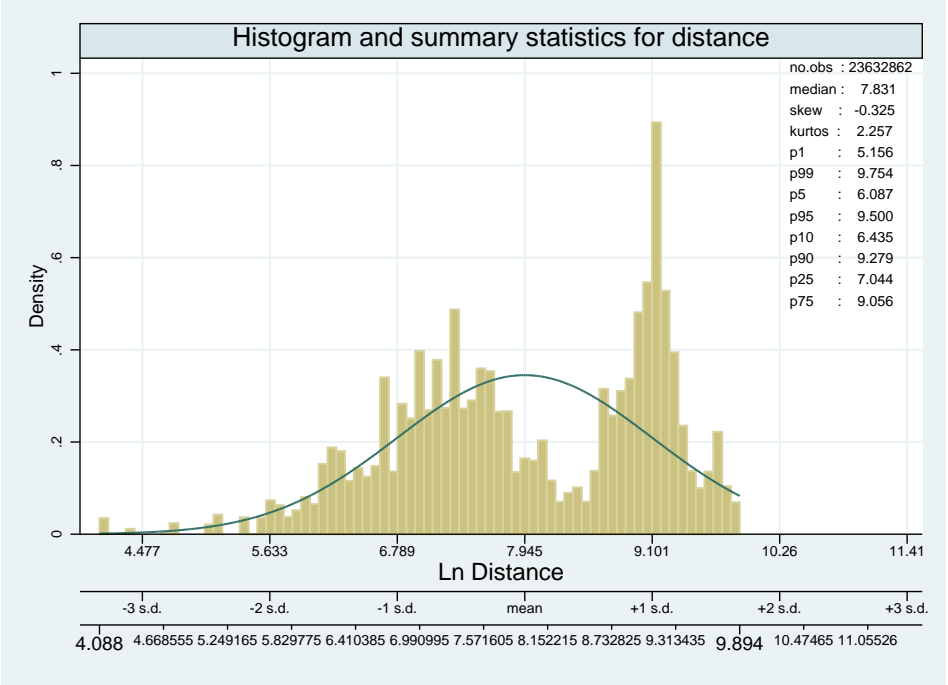

Figure 4: Histogram and summary statistics for distance

Table 9: Correlation table

\begin{tabular}{lccc}
\hline \multicolumn{1}{c}{ Variables } & Skill abundance $(\ln (\mathrm{S} / \mathrm{U}))$ & Ln GDP per capita & Ln Distance \\
\hline Skill abundance $(\ln (\mathrm{S} / \mathrm{U}))$ & 1.000 & & \\
& & & \\
Ln GDP per capita & 0.244 & 1.000 & \\
Ln Distance & $(0.000)$ & & \\
& -0.204 & -0.121 & 1.000 \\
\hline
\end{tabular}


List of exporters

\begin{tabular}{|c|c|c|c|}
\hline Argentina & Ecuador & Kyrgyz Republic & Peru \\
\hline Armenia & Spain & Cambodia & Philippines \\
\hline Australia & Estonia & Korea, Rep. & Poland \\
\hline Austria & Finland & Lebanon & Portugal \\
\hline Azerbaijan & France & Sri Lanka & Paraguay \\
\hline Bulgaria & United Kingdom & Lithuania & Romania \\
\hline Bosnia and Herzegovina & Georgia & Latvia & Russian Federation \\
\hline Brazil & Greece & Macao & Singapore \\
\hline Canada & Guatemala & Morocco & Slovak Republic \\
\hline Switzerland & Guyana & Madagascar & Slovenia \\
\hline Chile & Hong Kong, China & Mexico & Sweden \\
\hline Costa Rica & Croatia & Macedonia, FYR & Syrian Arab Republic \\
\hline Cuba & Hungary & Mauritius & Thailand \\
\hline Cyprus & India & Malaysia & Tajikistan \\
\hline Czech Republic & Ireland & Netherlands & Trinidad and Tobago \\
\hline Germany & Israel & Norway & Turkey \\
\hline Denmark & Italy & Pakistan & Uruguay \\
\hline Dominican Republic & Kazakhstan & Panama & South Africa \\
\hline \multicolumn{4}{|l|}{ List of importers } \\
\hline Argentina & Spain & Korea, Rep. & Oman \\
\hline Australia & Finland & Sri Lanka & Peru \\
\hline Austria & France & Lithuania & Poland \\
\hline Bolivia & Gabon & Latvia & Portugal \\
\hline Brazil & United Kingdom & Macao & Romania \\
\hline Central African Republic & Greece & Morocco & El Salvador \\
\hline Canada & Guatemala & Madagascar & Slovak Republic \\
\hline Switzerland & Hong Kong, China & Mexico & Slovenia \\
\hline Chile & Honduras & Macedonia, FYR & Sweden \\
\hline China & Croatia & Mauritius & Togo \\
\hline Colombia & Hungary & Malawi & Thailand \\
\hline Cyprus & India & Malaysia & Tunisia \\
\hline Germany & Ireland & Nicaragua & Turkey \\
\hline Denmark & Italy & Netherlands & Uruguay \\
\hline Ecuador & Jordan & Norway & United States \\
\hline Egypt, Arab Rep. & Japan & & \\
\hline
\end{tabular}

